\title{
A Reduction in B, T, and Natural Killer Cells Expressing CD38 by TAK-079 Inhibits the Induction and Progression of Collagen- Induced Arthritis in Cynomolgus Monkeys ${ }^{\text {[ }}$
}

\author{
Wouter Korver, Mary Carsillo, Josh Yuan, Neeraja Idamakanti, Matthew Wagoner, Pu Shi,
} Cindy Q. Xia, Glennda Smithson, Lachy McLean, Jonathan Zalevsky, and (1)Eric R. Fedyk

Takeda Pharmaceuticals Incorporated, Cambridge, Massachusetts

Received February 7, 2019; accepted May 8, 2019

\begin{abstract}
Ectoenzyme CD38 is increased on lymphocytes in response to an antigenic challenge and it is hypothesized that targeting these activated lymphocytes could ameliorate pathologic activities in autoimmune diseases. The cynomolgus monkey is an appropriate model for assessing potential effects of targeting CD38 in humans because these species exhibit similar expression profiles. TAK-079 is a human monoclonal antibody $\left(\operatorname{lgG}_{1 \lambda}\right)$ that binds to CD38 and lyses bound cells by complement-dependent cytotoxicity and antibody-dependent cell-mediated cytotoxicity. TAK-079 binds to monkey CD38 with an affinity at EC Fo $_{5.5} \mathrm{nM}$, and the potential activity of TAK-079 was investigated in a monkey collagen-induced arthritis model of autoimmune disease. Prophylactic administration of TAK-079 (3 mg/kg i.v. weekly) was well tolerated and prevented arthritis development compared with vehicle-treated control animals, which exhibited progressive disease with radiographic damage and worsening clinical scores over the study course. Therapeutic treatment of arthritic monkeys with TAK-079 (3 mg/kg i.v. weekly) was also well tolerated and reduced disease progression and symptoms. Arthritis scores and joint swelling were significantly lower than
\end{abstract}

the vehicle control, accompanied by decreases in blood levels of C-reactive protein, alkaline phosphatase, and natural killer, B, and $\mathrm{T}$ cells. Histopathology, morphometry, and radiology revealed significantly less joint damage in animals exposed prophylactically to TAK-079 treatment compared with vehicle-treated animals and significantly less damage in animals treated therapeutically with TAK-079 or dexamethasone $(0.1 \mathrm{mg} / \mathrm{kg}$ oral gavage daily), illustrating potential disease-modifying activity. In conclusion, these data indicate that depletion of CD38-expressing cells could be a therapeutic mechanism for treating autoimmune diseases.

\section{SIGNIFICANCE STATEMENT}

This study demonstrates that targeting CD38-expressing leukocytes with a cytolytic antibody can ameliorate autoimmune disease in cynomolgus monkeys. The study gives a unique perspective into this therapeutic strategy because the three other anti-CD38 cytolytic antibodies in clinical development (daratumumab, isatuximab, and MOR202) cannot be tested in similar models because they do not crossreact with CD38 expressed by new world primates.

\section{Introduction}

Autoantibodies mediate the pathogenesis of many autoimmune diseases, including rheumatoid arthritis (RA) (Deane, 2014) and systemic lupus erythematosus (SLE) (Kurts et al., 2013), directly by binding to tissue antigens and indirectly via the deposition of immune complexes (Martin and Chan, 2006). These autoantibodies are produced by transient, short-lived plasmablasts and plasma cells in secondary lymphoid tissues and by long-lived plasma cells and are entrenched in supportive niches within the bone marrow (Radbruch et al., 2006; Nutt et al., 2015). Pharmacologic modulation of plasma cells is

This research was supported by Takeda Pharmaceuticals Incorporated.

All authors were employees of Takeda Pharmaceuticals International until completion of these studies and/or the manuscript.

https://doi.org/10.1124/jpet.119.256602.

S This article has supplemental material available at jpet.aspetjournals.org. challenging because these cells are not actively cycling, cease expressing most surface antigens (e.g., CD20), and exhibit a long half-life (i.e., low turnover). Consequently, most existing therapeutics affect plasma cells and antibody production indirectly by modulating progenitors of these cells, e.g., rituximab (anti-CD20) targets B lymphocytes and belimumab inhibits short-lived plasmablasts from proliferation (Hale et al., 2018). Both methods can reduce autoantibody production; however, this effect manifests slowly (e.g., months to years) (Stohl et al., 2012) because of the relatively long half-life of pre-existing plasma cells. In contrast, plasma cells are sensitive to proteasome inhibition. A clinical study has demonstrated that the proteasome inhibitor bortezomib can deplete plasma cells, decrease autoantibodies, and ameliorate disease activity in patients with refractory SLE within weeks. However, gastrointestinal and neurologic adverse events restrict the use of bortezomib

ABBREVIATIONS: TAK-079, a human monoclonal antibody to CD38 of the IgG1 isotype, containing lambda light chains; ALP, alkaline phosphatase; CIA, collagen-induced arthritis; CRP, C-reactive protein; DIP, distal interphalangeal; FACS, fluorescence-activated cell sorter; mAb, monoclonal antibody; MCP, metacarpophalangeal; NK, natural killer; PD, pharmacodynamics; PIP, proximal interphalangeal; PK, pharmacokinetics; RA, rheumatoid arthritis; RBC, red blood cell; SLE, systemic lupus erythematosus. 
within these patients, presumably because of proteasome inhibition in neurons and epithelial cells (Alexander et al., 2015; Sjöwall et al., 2017). Consequently, a mechanism that specifically targets plasma cells could provide a safer and more effective method for reducing autoantibodies.

The CD38 antigen is a type II glycoprotein, which is highly expressed by plasma cells and plasmablasts and to a lesser magnitude by $B$ regulatory cells, natural killer (NK) cells, T regulatory cells, monocytes, and plasmacytoid dendritic cells in peripheral blood from healthy subjects (Krejcik et al., 2016) and patients with RA or SLE (Banchereau et al., 2016; Kubo et al., 2017; Cole et al., 2018). Analysis of synovial biopsies revealed that CD38 is expressed at higher levels in patients with RA and SLE than those with undifferentiated arthritis, osteoarthritis, reactive arthritis, ankylosing spondylitis, psoriatic arthritis, and crystal-induced arthritis (Kraan et al., 1999; Vital et al., 2011). Recent transcriptional profiling studies of blood from patients have identified up to 13 distinct signatures (i.e., phenotypes) of SLE (Banchereau et al., 2016) and have concluded that disease activity correlated most positively with the level of CD38-expressing plasmablasts in peripheral blood.

In patients with SLE treated with rituximab and oral steroids, the level of CD38-expressing plasmablasts in peripheral blood was the best predictor of time to relapse. Moreover, circulating Ig-secreting cells that express high levels of CD38 were identified in the peripheral blood of patients with active SLE, and the level of this plasma cell subset during treatment was associated with decreases in anti-double-stranded DNA antibody levels, proteinuria, and SLE disease activity (Grammer et al., 2003). Collectively, these data indicate that specifically reducing CD38expressing cells could be an effective strategy for treating autoimmune diseases such as RA and SLE.

TAK-079 is a fully human $\operatorname{IgG}_{1 \lambda}$ monoclonal antibody (mAb) that binds to both human and monkey CD38 and depletes cells by antibody-dependent cell-mediated cytotoxicity and complement-dependent cytotoxicity (Smithson et al., 2017). The addition of TAK-079 to blood or bone marrow samples from patients with RA (Wang et al., manuscript in preparation) or SLE (Wang et al., 2016) depleted $80 \%$ of plasma cell populations, including short- and long-lived plasma cells. Additionally, the number of cells producing autoantigenspecific antibodies was dramatically reduced, with VH4-34 9G4+ antibodies, anti-Ro antibody, and anti-double-stranded DNA antibody decreased by $70 \%, 70 \%$, and $80 \%$, respectively. The anti-human CD38 mAb daratumumab also depletes CD38expressing plasmablasts and plasma cells in samples from patients with SLE and RA in a dose-dependent manner in vitro (Cole et al., 2018). In contrast to daratumumab (European Medicines Agency's Committee for Medicinal Products for Human Use, 2016), TAK-079 crossreacts with CD38 expressed by cynomolgus monkeys, which provides a unique opportunity to determine if reducing the level of cells expressing CD38 would affect inflammation and tissue damage in a primate model of autoimmune disease.

\section{Materials and Methods}

Antibodies. TAK-079 was available at Takeda. Fluorochromeconjugated anti-mouse IgG was purchased from Jackson Immunoresearch Laboratories (West Grove, PA). Pharm Lyse buffer was obtained from BD Biosciences (San Jose, CA). Alexa Fluor 647conjugated TAK-079, unconjugated antibodies to TAK-079, and humanized control antibody with different antigen specificity but the same IgG1 fragment crystallizable region were generated at Takeda. The secondary antibody for the monkey tissue crossreactivity investigation was rabbit anti-TAK-079 (generated at Takeda). The negative control human IgG1 was obtained from Millipore Bioscience Research Reagents (Temecula, CA).

Immunohistochemistry of Tissues. The expression profile of the CD38 protein was compared across 15 different types of tissues collected from healthy human and cynomolgus monkey donors using immunohistochemistry. The quality of each tissue for detecting CD38 was verified by using a positive-control antibody against the related transmembrane receptor CD31 (Dako North America, Inc., Carpinteria, CA). Sections $(5 \mu \mathrm{m})$ were cut from fresh-frozen tissue samples embedded in O.C.T. Compound (Sakura Finetek USA, Inc., Torrance, CA) and fixed in acetone for 10 minutes at room temperature. Just before staining, slides were fixed for 10 seconds in $10 \%$ neutral buffered formalin. Acetone/formalin-fixed cryosections were rinsed twice in PBS and incubated for 20 minutes with a protein block (PBS; $0.5 \%$ casein; $5 \%$ human gamma globulins; $0.02 \%$ goat IgG; $1 \mathrm{mg} / \mathrm{ml}$ heat-aggregated human IgG) designed to reduce nonspecific binding. Unconjugated TAK-079 or negative control human IgG1 was applied to sections at 5 or $25 \mu \mathrm{g} / \mathrm{ml}$ and incubated at room temperature for 1 hour. The slides were then rinsed twice with PBS and an indirect immunoperoxidase procedure was performed to detect these primary reagents. The secondary antibody, rabbit anti-TAK-079, was then applied at $5 \mu \mathrm{g} / \mathrm{ml}$ for 30 minutes and rinsed twice with PBS. Endogenous peroxidase was blocked by incubating the slides for 5 minutes with the peroxidase solution provided in the Dako EnVision + Kit and then rinsing twice with PBS. The slides were then treated for 30 minutes with the peroxidase-labeled goat antirabbit IgG polymer supplied in the Dako EnVision+ Kit, rinsed twice with PBS, and treated for 8 minutes with the substrate-chromogen (3,3'-diaminobenzidine) solution supplied in the Dako EnVision+ Kit. All slides were rinsed with tap water, counterstained with hematoxylin, washed, blued in saturated lithium carbonate, washed, dehydrated through alcohols, cleared in xylene, and cover slipped. Staining intensity was graded semiquantitatively by a blinded American College of Veterinary Pathologists certified anatomic pathologist.

TAK-079 Binding to Recombinant CD38. CHO-K1 cells stably expressing monkey CD38 were generated to study cell surface binding of anti-CD38 antibodies. CHO-K1 cells (Lonza, Morristown, NJ) were transfected with full-length cDNA clones of cynomolgus monkey CD38 (Origene Technologies, Rockville, MD). After selection, the pools were sorted by flow cytometry and the highest cynomolgus monkey CD38-expressing clones (top 15\% mean fluorescence intensities) were used for binding studies. In a 96 -well round-bottom plate, 200,000 cells per well were plated and stained with $66.7 \mathrm{nM}$ of directly conjugated Alexa Fluor 488 to antibodies in $50 \mu \mathrm{l}$ of fluorescence-activated cell sorter (FACS) buffer ( $1 \%$ bovine serum albumin in PBS) on ice for 30 minutes to 1 hour. Cells were washed three to four times in a final volume of 200-250 $\mu$ l of FACS buffer. The final cell pellet was resuspended in $100 \mu \mathrm{l}$ of FACS buffer containing 1\% paraformaldehyde. Samples were evaluated on a FACSCanto II HTS sampler (BD Biosciences) and analyzed using FlowJo software (Tree Star Inc., Ashland, OR).

Flow Cytometry of Cell Lines and Whole Blood. For the staining of cell lines, cells were resuspended at $2 \times 10^{6} / \mathrm{ml}$ in FACS buffer (5\% fetal bovine serum and $0.05 \%$ sodium azide) in Dulbecco's PBS without calcium and magnesium (VWR, West Chester, PA) and $200-\mu \mathrm{l}$ samples were stained with the appropriate mAbs at $4^{\circ} \mathrm{C}$ for 30 minutes. Samples were washed with FACS buffer and analyzed by flow cytometry using the BD FACSCalibur platform (BD Biosciences). For whole blood, 200- $\mu \mathrm{l}$ samples from monkeys were stained with the appropriate $\mathrm{mAb}$ at $4^{\circ} \mathrm{C}$ for 30 minutes. Red blood cells (RBCs) were lysed with BD FACS lysing solution, and samples were then washed 
with FACS buffer and analyzed by flow cytometry. In all cases, antibodies were used at saturating concentrations, and in many cases up to four antibodies were used per sample.

TAK-079 Activity in Whole Blood from Cynomolgus Monkeys. Cynomolgus monkey whole blood was obtained from Charles River Laboratories (Wilmington, MA). For binding assays, anticoagulated cynomolgus monkey peripheral whole blood $(100 \mu \mathrm{l})$ was incubated with increasing concentrations of TAK-079 antibody (43-690 nM) for 30 minutes at room temperature. Binding of TAK-079 to the cells was assayed using a phycoerythrin-labeled goat anti-human IgG fragment crystallizable antibody (Thermo Fisher Scientific, Waltham, MA). Following binding of the antibodies, RBCs were lysed using fixative-free high yield lyse (Thermo Fisher Scientific). The cells were then washed twice with magneticactivated cell sorting buffer containing $0.5 \%$ bovine serum albumin (Miltenyi Biotec, Gaithersburg, MD). Cell staining data were collected by flow cytometry using an Attune NxT Acoustic Focusing Cytometer (Thermo Fisher Scientific) and analyzed using FlowJo software (Tree Star Inc.).

For cytolysis assays, $90 \mu \mathrm{l}$ of the whole blood was plated into each well on 96-well U-bottom plates. Immediately after plating, the whole blood was treated with $0.69,2.06,6.17,18.52,55.56,166.67$, and $500 \mathrm{nM}$ of TAK-079 or PBS as the control for 6,24 , and 48 hours. At each time point, the control and testing molecule treated whole blood in the 96-well U-bottom plate was transferred to a deep-well plate for RBC lysis. After lysis, cells were resuspended in stain buffer with CD16/Brilliant Violet 605, CD56/phycoerythrin, and CD38/fluorescein isothiocyanate antibodies for surface marker staining. Cells were protected against light and incubated at $4^{\circ} \mathrm{C}$ for 20 minutes. After incubation, cells were centrifuged at $350 \mathrm{~g}$ at room temperature for 5 minutes and washed with 1X Annexin V binding buffer. Then, the cells were resuspended in $1 \mathrm{X}$ Annexin $\mathrm{V}$ binding buffer containing Annexin V Alexa Fluor 647 at room temperature for 20 minutes. The stained cells were analyzed by a BD FACSCelesta flow cytometer (BD Biosciences), and the data were recorded with BD FACSDiva software, version 8.0.1. The NK cell viability at each testing concentration and the half-maximal inhibitory concentration values of TAK-079 NK cell depletion at each time point were graphed and fitted with GraphPad Prism 7.04 (GraphPad, La Jolla, CA).

Dose-Range Finding Studies in Healthy Monkeys. In two investigations, groups $(n=10)$ of healthy, purpose-bred, experimentally naive cynomolgus monkeys received vehicle control and $0,0.1$, 0.3 , and $1 \mathrm{mg} / \mathrm{kg}$ of TAK- 079 weekly or 3,30 , and $80 \mathrm{mg} / \mathrm{kg}$ of TAK-079 biweekly via a 20 -minute intravenous infusion (Charles River Laboratories). The animals were evaluated for changes in clinical signs including twice daily cage side observations, postdose observations, weekly detailed examinations, food consumption, and weekly body weight. Blood samples were collected pre- and postdose for evaluation of pharmacokinetics (PK), pharmacodynamics (PD), and primate antihuman antibodies. Investigations were conducted in cynomolgus monkeys in accordance with the testing facility standard operation procedures (Charles River Laboratories), which adhere to the regulations outlined in the Animal Welfare Act [Final Rules: Animal Welfare; 9 CFR, Parts 1, 2, and 3 (https:// www.nal.usda.gov/awic/final-rules-animal-welfare-9-cfr-parts-1-2-and3 )] and the conditions specified in the Guide for the Care and Use of Laboratory Animals (https://grants.nih.gov/grants/olaw/guide-forthe-care-and-use-of-laboratory-animals.pdf).

Bioanalytical Procedure for Determination of TAK-079 Serum Concentrations. The concentration of TAK-079 in cynomolgus monkey serum was determined by an indirect ELISA method utilizing a 96 -well microtiter format. The plate was coated with a mouse anti-idiotypic antibody against TAK-079. Blanks, standards, and quality control samples containing TAK-079 at various concentrations as well as monkey serum samples were added to the coated microtiter plate and incubated for 55-65 minutes at room temperature. After washing, the detection antibody (peroxidase-conjugated AffiniPure mouse anti-human IgG) was added, and incubated on the plate for an additional 55-65 minutes. The plate was washed again, and tetramethylbenzidine was added to the wells to generate a chromophore; the development of color was stopped by the addition of $2 \mathrm{~N}$ sulfuric acid stopping solution. The absorbance at $450 \mathrm{~nm}$ was measured, and the TAK-079 concentrations were calculated using a four-parameter logistic weighted $\left(1 / y^{2}\right)$ standard calibration curve.

Bioanalytical Procedure for Determination of Anti-TAK-079 Antibodies. Anti-TAK-079 antibody screening of cynomolgus monkey serum was determined by a qualitative, enhanced chemiluminescence method. Undiluted cynomolgus monkey serum samples were incubated with $300 \mathrm{mM}$ acetic acid. After acid dissociation, samples were incubated in a mixture of biotinylated TAK-079, TAK-079 labeled with SULFO-TAG, and $1.5 \mathrm{mM}$ Trizma base to neutralize the acid and form an immune complex. This complex was then added to a streptavidin-coated MSD plate (Meso Scale Discovery, Rockville, MD) and allowed to bind. After washing, the complex was detected by the addition of MSD Read Buffer T to the plate and subsequent excitation of the SULFO-TAG (Meso Scale Discovery) via an electrochemical reaction of tris(bipyridine)ruthenium(II) chloride to generate luminescence, which was read using MSD Sector 6000 . The quantity of luminescence correlates with the level of cynomolgus monkey anti-TAK-079 antibodies present in the serum of individual samples. The minimum required dilution of cynomolgus monkey serum for this assay was set at 1/33. For graphical representation, results from each animal were plotted as a function of antibody titer and enrollment day. Serum samples with values at or below the plate-specific cut point were plotted using a nominal titer value to facilitate plotting.

Monkey Collagen-Induced Arthritis Model. Ethically responsible use of nonhuman primates was ensured by modeling the PD responses of cynomolgus monkeys to TAK-079 and then extrapolating the minimum number of animals required per treatment group to yield statistically significant differences in $\mathrm{PD}$ responses. Thirty-five naive female cynomolgus monkeys, ranging from 3 to 4 years old, 2.5-3.3 kg, were obtained from Biomedical Research (GZ) Ltd. (SNBL, Guangdong, China). Upon receipt, a health inspection was performed on each animal by the contract research organization (PharmaLegacy Laboratories, Inc., Shanghai, China). The animals were housed one per cage and acclimated for a minimum of 14 days prior to the commencement of the experimental procedures. The animal room was maintained at a temperature of $20-29^{\circ} \mathrm{C}$ with a relative humidity of $40 \%-70 \%$, and a 12-hour light/dark cycle. Animals were trained for receiving intravenous infusions or oral gavage before study initiation. Monkeys had ad libitum access to vegetables, fruit, chow (Shanghai Shilin Biologic Science \& Technology Co. Ltd., Shanghai, China), and water according to a conventional protocol. Cages were stratified within the racks to reduce the effect of any environmental influences on the study. This experimental design, all study protocols, and experimental procedures were reviewed and approved by the host Ethics Committee (PharmaLegacy Laboratories, Inc.), in accordance with Chinese law on animal experimentation.

Monkeys were selected for the study based on prescreening criteria. One naive animal was not administered collagen and was maintained as the negative control for disease induction. The remaining animals were subcutaneously administered bovine type II collagen (Sichuan Deebio Pharmaceutical Co., Sichuan, China) dissolved in $0.01 \mathrm{~N}$ acetic acid (SPGC Sinopharm Chemical Reagent Co., Ltd, Shanghai, China) to a final concentration of $4 \mathrm{mg} / \mathrm{ml}$ (Mihara et al., 2001; Kato et al., 2008; Uchiyama et al., 2008a,b) on days 0 and 21. Collagen was emulsified with an equal volume of Complete Freund's Adjuvant (Sigma-Aldrich, St. Louis, MO). The animals were presedated with ketamine ( $4 \mathrm{mg} / \mathrm{kg}$, intramuscular injection), and additional anesthesia was applied, if needed, with $1.5 \%-5 \%$ isoflurane via an inhalation anesthesia machine, Matrx VIP3000 Isoflurane (Midmark, Torrance, $\mathrm{CA}$ ), to effect an oxygen fow rate of 0.8-1.5 1. Any ulcerative skin lesions developing at the immunization sites were treated with iodine each time an animal was sedated in order to prevent infection. 


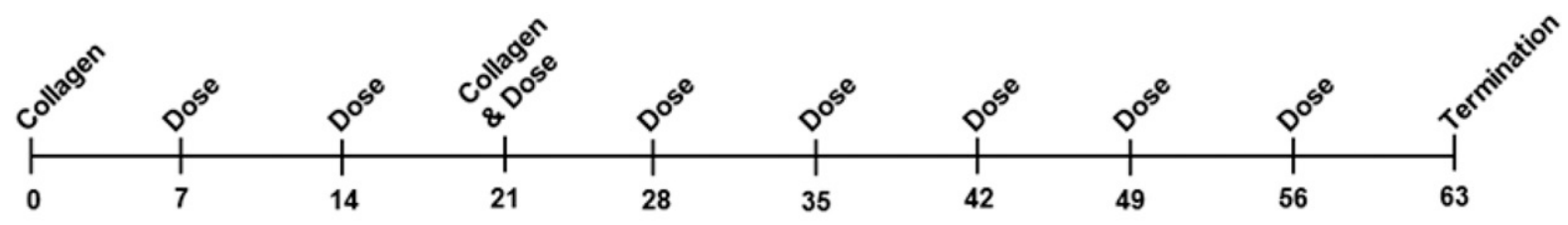

Naïve ( $n=1)$

Prophylactic
TAK-079 $(n=7)$

Therapeutic

TAK-079 $(n=5)$

Vehicle

Control $(n=5)$

Therapeutic

Dexamethasome $(n=4)$ $\mathrm{x} \quad \mathrm{x}$

$x \quad x$

$\mathrm{x}$

$x$

$\mathrm{x}$

$\mathrm{X}$

$\mathrm{x}$

$\mathrm{x}$

$\mathrm{x}$

$\mathrm{x}$

$\mathrm{x}$

$\mathrm{x}$

$\mathrm{X}$

\section{$x x x x x x x x x x x x x x x x x x x x x x x x x x x x x x x x x x x x x x x x x x x x$}

Fig. 1. Schedule of events.
Eight animals receiving collagen were assigned to the prophylactic TAK-079 group on day 0 . The prophylactic TAK-079 animals received weekly infusions of $3 \mathrm{mg} / \mathrm{kg}$ TAK-079 starting from day 7 onward, with the last dose administered on day 56 , for a total of eight doses. Animals in this group were sacrificed on day 63 . The remaining immunized animals were treated as one group and received a weekly 30 -minute intravenous infusion of vehicle (saline) starting from day 7 until an animal reached or exceeded $\geq 15 \%$ of the maximum clinical arthritis score. At this point, the animal was enrolled into the vehicle control group $(n=5)$, therapeutic TAK-079 group $(n=5)$, or therapeutic dexamethasone group $(n=4)$, and enrollment continued on a rolling basis due to the time differences in disease onset. For animals enrolled in the vehicle control group, weekly infusions of vehicle were performed for 5 weeks. Animals in this group were sacrificed 7 days after the last dose. For animals enrolled in the therapeutic TAK-079 group, infusions were performed weekly for 5 weeks. Animals in this group were sacrificed 7 days after the last dose. Animals enrolled in the therapeutic dexamethasone group received daily oral gavage for 5 weeks and were sacrificed 1 day after the last dose to ensure that animals in the three therapeutic groups were exposed to agents for an identical duration (Fig. 1). The animals were observed daily for signs of ill health and general reaction to treatments. All exceptions to normal healthy appearance and behavior were recorded and detailed in standard clinical observation forms.

Assessment of Arthritic Activity. The body weight of the monkeys was measured once during the acclimation period (5 days prior to the start of the experiment), on the day prior to each cycle of disease induction, and then once weekly through the end of the study. The number of animals in a group with joint swelling was recorded on days 0 and 21, and then daily through the end of the study. The number of proximal interphalangeal (PIP) joints (each hand and foot, respectively) with joint swelling was recorded for each animal on days 0 and 21 , and then once weekly through the end of the study. The longitudinal and transverse axes of PIP joints of the fore and hind limbs (without the thumb) were measured with calipers on days 0 and 21 , and then once weekly after disease onset through the end of study for all PIP joints with arthritis. The mean oval area of 16 PIP joints was calculated and adopted as individual data. The oval area of each PIP joint was calculated using the following formula: oval area $=$ longitudinal axis $\times$ transverse axis $\times 3.14 \times 1 / 4$. The percentage of oval area change and joint swelling was calculated using the following formulas: \% change of oval area $=($ mean oval area on day $X /$ mean oval area on the day of first sensitization $) \times 100$ and joint swelling $=($ mean oval area on day $X$ - mean oval area on the day of first sensitization).

Clinical Arthritis Score. The severity of arthritis of each limb in monkeys was scored on days 0 and 21 , and then once weekly through the end of the study according to these criteria: normal (0); mild arthritis, subtle but definite (1); moderate swelling (2); and severe arthritis with significant swelling and/or noticeable joint deformity (3). The following joints of each paw were examined and scored: 15 joints in total including five metacarpophalangeal (MCP) joints, four PIP joints, five distal interphalangeal (DIP) joints, and one wrist/ankle. The knee/elbow of each limb was also evaluated for disease severity. The arthritic score of each animal was the total score of each individual joint with a maximum score of $192(16 \times 3 \times$ 4 , where $16=$ total number of joints plus the knee/elbow for each limb, 3 = maximum score for each individual joint, and $4=$ number of limbs per monkey).

Blood Collection and Analysis. Blood samples were used for complete blood count, blood chemistry, and serum preparation for antibody, PK, and antidrug antibody measurements, and were collected from animals at the time points indicated below. For animals from the naive group and the prophylactic TAK-079 group, blood was collected twice, once prior to dosing and once on the following day, during weeks 1 and 5, just before TAK-079 administration during weeks $2,3,4,6,7$, and 8 , and when animals were terminated during week 9 . All other animals had weekly blood collections up until the time that the disease reached the threshold of $15 \%$ of maximum arthritis score. After assignment to the vehicle group, therapeutic TAK-079 group, or therapeutic dexamethasone group, blood samples were collected weekly just prior to dosing and at termination. In addition, samples were collected on the day after the first dose of drug and the day after the fifth dose. For the vehicle control, prophylactic TAK-079, therapeutic TAK-079, and dexamethasone groups, blood samples for flow cytometry were collected before the first dose (on the day of infusion), on the day following the first dose, before the second dose (on the day of dosing), before the fifth dose (on the day of dosing), and on the day of termination. For the therapeutic TAK-079 group, blood samples for flow cytometry were collected before the first dose of drug, on the day following the first dose, before the eighth dose, before the 29th dose, and on the day of termination.

Radiographic Examination. Examinations were performed for each joint (DIP, PIP, first interphalangeal, and MCP sites typically involved in human RA and lupus arthritis) on the hands and feet of live, anesthetized animals at study termination. Radiographic grading was carried out in a blinded fashion, based on a 0-4 grading system as follows: $0=$ normal; $1=$ minor deformity in articular cartilage layers and/or subchondral bone regions; $2=$ severe deformity in articular cartilage layers and subchondral bone regions, a small amount of osteophytes present at periosteal surfaces, and joint margins are fuzzy but still visible; $3=$ the same 
TABLE 1

A comparison of TAK-079-bound cells in human and monkey tissues

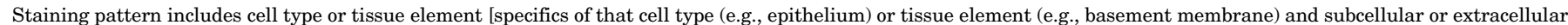

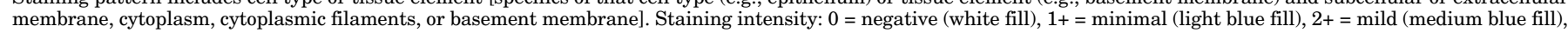
and $4+=$ marked (dark blue fill).

\begin{tabular}{|c|c|c|c|c|c|c|c|c|c|c|}
\hline \multirow[b]{3}{*}{ Tissue } & \multicolumn{5}{|c|}{ Human } & \multicolumn{5}{|c|}{ Monkey } \\
\hline & \multicolumn{2}{|c|}{ TAK-079 } & \multicolumn{2}{|c|}{ Human IgG1 Control } & \multirow{2}{*}{ TAK-079-Bound Cells } & \multicolumn{2}{|c|}{ TAK-079 } & \multicolumn{2}{|c|}{ Human IgG1 Control } & \multirow[b]{2}{*}{ TAK-079-Bound Cells } \\
\hline & $5 \mu \mathrm{g} / \mathrm{ml}$ & $25 \mu \mathrm{g} / \mathrm{ml}$ & $5 \mu \mathrm{g} / \mathrm{ml}$ & $25 \mu \mathrm{g} / \mathrm{ml}$ & & $5 \mu \mathrm{g} / \mathrm{ml}$ & $25 \mu \mathrm{g} / \mathrm{ml}$ & $5 \mu \mathrm{g} / \mathrm{ml}$ & $25 \mu \mathrm{g} / \mathrm{ml}$ & \\
\hline Bone marrow & $3 \mathrm{C} / \mathrm{M}$ & $2+\mathrm{M}$ & 0 & 0 & $\begin{array}{l}\text { Bone marrow cells, } \\
\text { possibly leukocytes }\end{array}$ & $1+\mathrm{C} / \mathrm{M}$ & $1+\mathrm{M}$ & 0 & 0 & $\begin{array}{c}\text { Few bone marrow } \\
\text { cells, possibly } \\
\text { leukocytes } \\
\end{array}$ \\
\hline Heart & 0 & 0 & 0 & 0 & & 0 & 0 & 0 & 0 & \\
\hline Colon & $3+\mathrm{C} / \mathrm{M}$ & $4+\mathrm{C} / \mathrm{M}$ & 0 & 0 & $\begin{array}{c}\text { Leukocytes, including } \\
\text { lymphocytes, in lamina } \\
\text { propria; some } \\
\text { endothelium } \\
\end{array}$ & $2+\mathrm{C} / \mathrm{M}$ & 0 & 0 & 0 & $\begin{array}{c}\text { Cells in lamina } \\
\text { propria, possibly } \\
\text { lymphocytes, some } \\
\text { endothelium }\end{array}$ \\
\hline Stomach & 0 & 0 & 0 & 0 & $\begin{array}{c}\text { Leukocytes, including } \\
\text { lymphocytes, in lamina } \\
\text { propria; some } \\
\text { endothelium }\end{array}$ & $1+\mathrm{C} / \mathrm{M}$ & $1+\mathrm{C}$ & 0 & 0 & $\begin{array}{c}\text { Spindle cells in lamina } \\
\text { propria, apparently } \\
\text { endothelium }\end{array}$ \\
\hline Small intestine & $4+\mathrm{C} / \mathrm{M}$ & $4+\mathrm{C} / \mathrm{M}$ & 0 & 0 & $\begin{array}{c}\text { Leukocytes, including } \\
\text { lymphocytes, in lamina } \\
\text { propria; some } \\
\text { endothelium }\end{array}$ & $2+\mathrm{C} / \mathrm{M}$ & $1+\mathrm{C} / \mathrm{M}$ & 0 & 0 & $\begin{array}{l}\text { Cells in lamina } \\
\text { propria, possibly } \\
\text { lymphocytes, some } \\
\text { endothelium }\end{array}$ \\
\hline Renal glomerulus & 0 & 0 & 0 & 0 & \begin{tabular}{l|} 
in lamina propria; \\
some endothelium
\end{tabular} & 0 & 0 & 0 & 0 & \\
\hline Renal tubule & 0 & 0 & 0 & 0 & & 0 & 0 & 0 & 0 & \\
\hline Liver & 0 & 0 & 0 & 0 & & 0 & 0 & 0 & 0 & \\
\hline Lymph node & $3+\mathrm{C} / \mathrm{M}$ & $4+\mathrm{C} / \mathrm{M}$ & 0 & 0 & $\begin{array}{c}\text { Cells in medullary } \\
\text { cords and sinuses; } \\
\text { possibly plasma cells; } \\
\text { few in cortex }\end{array}$ & $4+M$ & $3+\mathrm{C}$ & 0 & 0 & $\begin{array}{l}\text { Cells in medullary } \\
\text { cords and sinuses, } \\
\text { fewer in cortex }\end{array}$ \\
\hline Lung & $3+\mathrm{C} / \mathrm{M}$ & $3+\mathrm{C} / \mathrm{M}$ & 0 & 0 & $\begin{array}{c}\text { Interstitial and } \\
\text { peribronchiolar cells }\end{array}$ & 0 & 0 & 0 & 0 & \\
\hline Pancreas & 0 & 0 & 0 & 0 & & 0 & 0 & 0 & 0 & \\
\hline Prostate & $3+\mathrm{C}$ & $3+\mathrm{C}$ & 0 & 0 & $\begin{array}{c}\text { Acinar epithelium; } \\
\text { some interstitial } \\
\text { leukocytes }\end{array}$ & 0 & 0 & 0 & 0 & \\
\hline & \multicolumn{5}{|c|}{ Human } & \multicolumn{5}{|c|}{ Monkey } \\
\hline & \multicolumn{2}{|c|}{ TAK-079 } & \multicolumn{2}{|c|}{ Human IgG1 Control } & & \multicolumn{2}{|c|}{ TAK-079 } & \multicolumn{2}{|c|}{ Human IgG1 Control } & \\
\hline Tissue & $5 \mu \mathrm{g} / \mathrm{ml}$ & $25 \mu \mathrm{g} / \mathrm{ml}$ & $5 \mu \mathrm{g} / \mathrm{ml}$ & $25 \mu \mathrm{g} / \mathrm{ml}$ & TAK-079-Bound Cells & $5 \mu \mathrm{g} / \mathrm{ml}$ & $25 \mu \mathrm{g} / \mathrm{ml}$ & $5 \mu \mathrm{g} / \mathrm{ml}$ & $25 \mu \mathrm{g} / \mathrm{ml}$ & TAK-079-Bound Cells \\
\hline Skin & 0 & 0 & 0 & \begin{tabular}{l|}
0 \\
\end{tabular} & & 0 & 0 & 0 & 0 & \\
\hline Uterus (cervix) & $2+\mathrm{C} / \mathrm{M}$ & $1+\mathrm{C} / \mathrm{M}$ & 0 & 0 & $\begin{array}{c}\text { Submucosal } \\
\text { leukocytes, probably } \\
\text { lymphocytes } \\
\end{array}$ & 0 & 0 & 0 & 0 & \\
\hline Uterus (endometrium) & 0 & 0 & 0 & 0 & & 0 & 0 & 0 & 0 & \\
\hline
\end{tabular}

C, cytoplasmic staining pattern; IgG1, immunoglobulin G1; M, membranous staining pattern.

types of changes observed in grade 2 but advanced further with a large amount of osteophytes present at periosteal surfaces and the joint cavity is indistinguishable or invisible; 4 = the same type of changes as in grade 3 but advanced further, the joint cavity becomes undetectable, bones appear sclerotic or ankylosing, and major disfiguration occurs.

Histopathology and Histomorphometry of Tissue from Arthritic Monkeys. Animals were euthanized by exsanguination under anesthesia at the end of the study. The paws, spleen, colon, and lymph nodes (mesenteric and inguinal) were collected and fixed in neutral buffered formalin. PIP and DIP joints were decalcified with $15 \%$ EDTA, dehydrated, and embedded in paraffin $(8$ blocks $/$ paw $\times 4$ paws $\times 22$ animals $=704$ blocks $)$. Frontal coronal sections of the joints were obtained using a rotary microtome (Leica Biosystems, Shanghai, China). Histopathology scoring was performed using toluidine blue-stained sections (Carolina Biologic,
Shanghai, China; $32 \times 22$ animals $=704$ slides) by a bone histopathologist in a blinded manner. The histology sections were qualitatively assessed for cell infiltration, pannus, cartilage lesion, and bone resorption on a five-point scale, wherein a score of $0=$ normal/negative for the feature, $1=$ a few scattered features, $2=$ mild incidence, $3=$ moderate incidence, and $4=$ severe $/$ marked incidence. Quantitative histomorphometry was performed using Osteomeasure software (OsteoMetrics, Inc., Atlanta, GA) interfaced with a Nikon Eclipse E400 light/fluorescent microscope and video subsystem (Nikon Instruments, Inc., Shanghai, China). Histomorphometric measurements of the articular area and surface were performed blinded, by a bone histopathologist, using toluidine blue-stained slides $(32 \times 22$ animals $=704$ slides $)$.

Statistical Analysis. Data are presented as mean \pm S.E.M. Statistical analyses were conducted with GraphPad Prism on each parameter among naive, model, reference drug (dexamethasone), and 
A
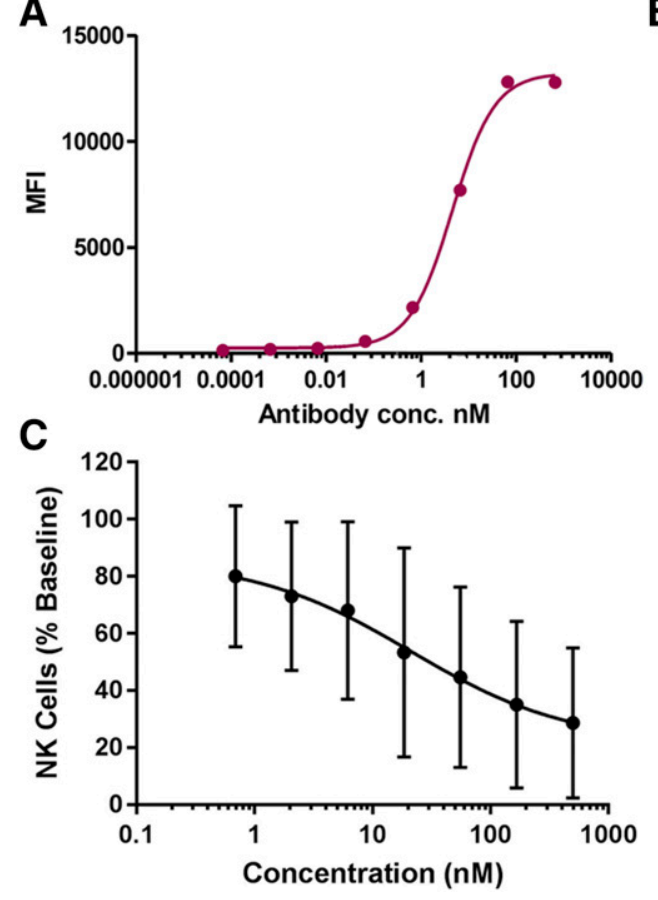

B

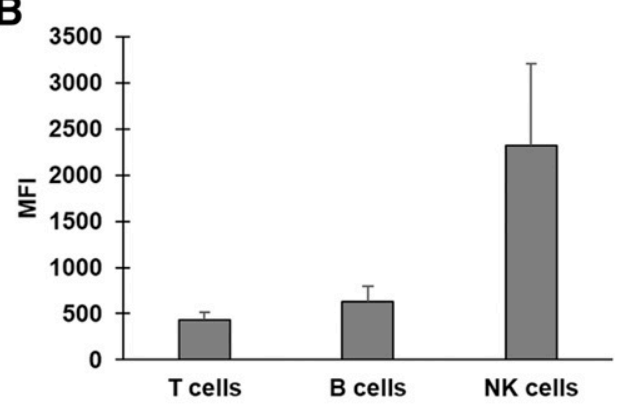

Fig. 2. A representative concentrationdependent binding curve of TAK-079 to CHO cells expressing recombinant cynomolgus monkey CD38 (A) and endogenous cynomolgus monkey CD38 expressed on CD3+ T lymphocytes, CD3-/CD20+ B lymphocytes, and CD3-/CD20-/CD16+ NK cells (B) $(n=3$, error bars denote S.D. from the mean). Mean levels of NK cells in whole blood from cynomolgus monkeys after incubation with TAK-079 for 48 hours in culture (C) $(n=3$, error bars denote S.D. from the mean). conc., concentration; MFI, mean fluorescence intensity; $n$, number of observations. test article groups. $P<0.05$ was considered significantly different. Post-hoc multiple comparisons among the group data were conducted in this study for differences identified by ANOVA to identify which treatment groups differed.

\section{Results}

The Expression Profile of CD38 in Cynomolgus Monkey. To determine if the cynomolgus monkey could be an adequate model for assessing the potential effects of targeting CD38 in humans, the expression profile of the CD38 antigen was compared across 15 different types of tissues collected from healthy human and cynomolgus monkey donors. Immunohistochemistry revealed that TAK-079 bound to mononuclear leukocytes in colon, stomach, small intestine, bone marrow, and lymph node, as well as in some endothelial cells in the lamina propria of colon, stomach, and small intestine in both species (Table 1). Conversely, in humans but not monkeys TAK-079 also bound to mononuclear leukocytes in lung, prostate, and uterus (cervix), and to prostate acinar epithelium. TAK-079 binding was not observed in heart, kidney, pancreas, skin, and endometrium of the uterus of either species. TAK-079 staining was generally moderate to marked $(3+$ to $4+)$ in intensity in human tissues and minimal to mild (1+ to $2+)$ in intensity in cynomolgus monkey tissues (Table 1), which could reflect the difference in affinities of TAK-079 for human versus monkey CD38 and/or differences in the magnitude of expression of CD38. The staining pattern was primarily cytoplasmic and cell membranes were stained in some cells (Table 1). Overall, it was concluded that the monkey was an adequate model species to assess the potential pharmacologic effect(s) of targeting CD38 in a model of autoimmune disease.

TAK-079 Binds to CD38 Expressed by Cynomolgus Monkeys. The amino acid sequence of the human CD38 protein exhibits $91 \%$ of amino acid identity with its cynomolgus monkey ortholog. A comparison of the binding epitope of TAK-079 in human CD38 with the corresponding sequence in monkey CD38 revealed a single amino acid substitution of a lysine with a glutamate at position 274 . To determine if TAK-079 could be used for assessing the potential effects of targeting CD38 in monkeys, monkey CD38 was expressed in CHO cells. TAK-079 bound to monkey CD38 with a halfmaximal $\mathrm{EC}_{50}$ of $4.5 \mathrm{nM}$ (Fig. 2A), which is sufficient for assessing the potential effects of specifically targeting CD38 in monkeys.

TAK-079 also bound to monkey $\mathrm{B}, \mathrm{NK}$, and T cells in whole blood. NK cells exhibited a higher mean fluorescent intensity than $\mathrm{B}$ and T cells (Fig. 2B), indicating that monkey NK cells express a higher density of CD38 per cell. After incubation within monkey whole blood in vitro, TAK-079 cytolysed NK cells in a dose-dependent manner (Fig. 2C), exhibiting a mean $\mathrm{EC}_{50}$ of $29.6 \mathrm{nM}$. This cytolytic activity, as well as the similarity in the expression profiles of CD38, illustrate that the cynomolgus monkey is a suitable model species for investigating the potential pharmacologic effect(s) of TAK-079 in vivo.

The Pharmacologic Effects of TAK-079 in Healthy Monkeys. To characterize the pharmacologic effects of TAK-079 in vivo, healthy cynomolgus monkeys were infused intravenously with TAK-079 at $0.1,0.3$, and $1 \mathrm{mg} / \mathrm{kg}$ weekly and at 3,30 , and $80 \mathrm{mg} / \mathrm{kg}$ biweekly for 3 months, and a subset of animals was monitored for 3 months after the last dose (Fig. 3A). For most animals, peak TAK-079 concentrations occurred at the end of the infusion and were dose proportional (Table 2). Exposure (the area under the concentration-time curve from dose administration to 366 hours postdose) at steady state generally increased in a dose-proportional manner in animals that did not exhibit anti-TAK-079 antibodies and accumulated 1.7- to 2.4-fold by week 13 (Table 2), which is consistent with decreased clearance due to the target-mediated drug disposition of 


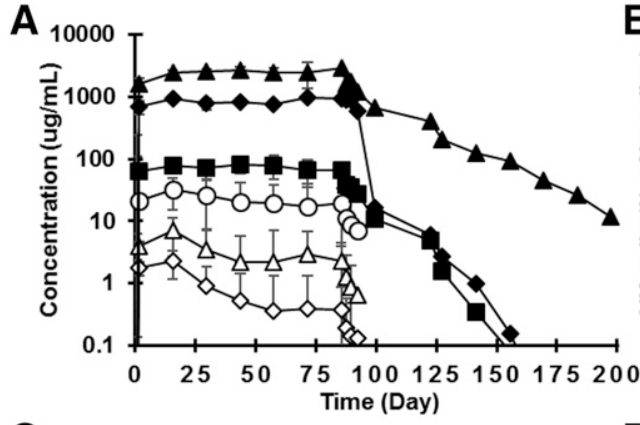

C

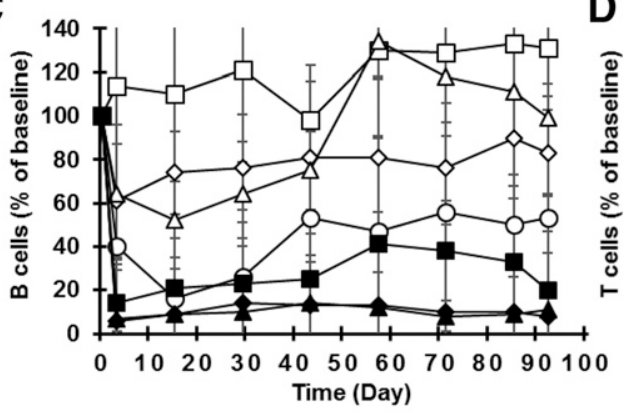

$\square$ - Vehicle control
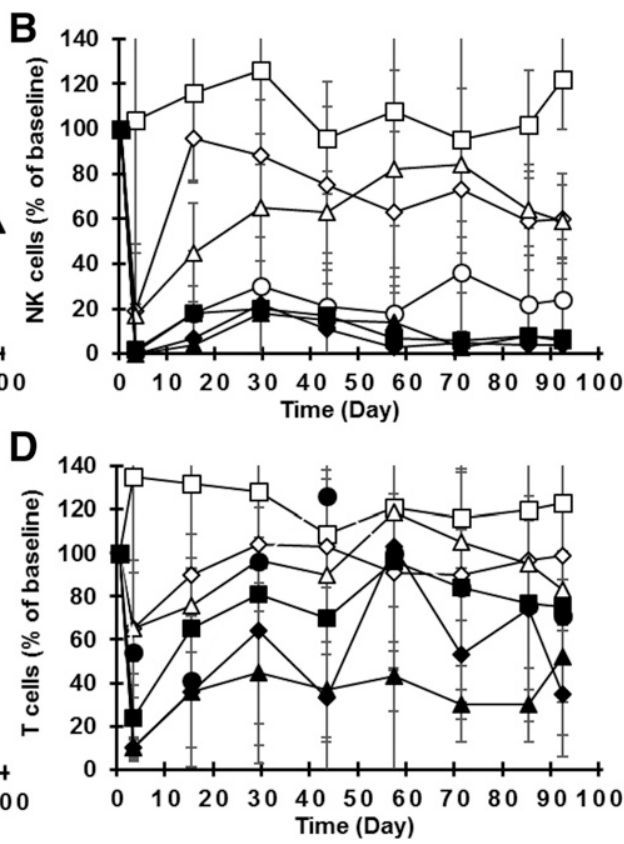

$\triangle$ TAK-079 $0.3 \mathrm{mg} / \mathrm{kg}$
Fig. 3. The mean concentration of TAK079 in serum from monkeys infused intravenously with TAK-079 (A) and percentage of change from predose baseline in mean absolute cell counts of CD20-/CD3-/ CD16+ NK cells (B), CD3-/CD20+ B cells (C), and CD3+ T cells (D) in peripheral blood of monkeys after intravenous infusion to TAK-079. Cohorts denoted with white symbols ( $n=7$ animals) were dosed weekly and with closed symbols ( $n=5$ animals) were dosed once every 2 weeks for 3 months. Error bars denote S.D.
TAK-079. The half-lives after the last doses of 3 and $80 \mathrm{mg} / \mathrm{kg}$ TAK-079 in animals that did not exhibit antiTAK-079 antibodies were 237 and 415 hours, respectively (Table 2). No gender differences in PK characteristics were observed.

The NK cell population expressed CD38 with a uniformly high density (Fig. 2B) and was reduced in peripheral blood after the first infusion of TAK-079 with an $\mathrm{ED}_{50}$ of $0.3 \mathrm{mg} / \mathrm{kg}$ (Fig. 3B) at a corresponding $C_{\max }$ of $7.78 \mu \mathrm{g} / \mathrm{ml}$ and an overall mean exposure of 665 hour $\mu \mathrm{g} / \mathrm{ml}$ at week 13 (Table 2). In contrast, the B cell population expressed CD38 heterogeneously with a lower median density than NK cells (Fig. 2B) and was reduced in peripheral blood after the initial infusion of TAK-079 with an $\mathrm{ED}_{50}$ of $1.0 \mathrm{mg} / \mathrm{kg}$ (Fig. 3C) at a corresponding $C_{\max }$ of $28.6 \mu \mathrm{g} / \mathrm{ml}$ and an overall mean exposure of 2700 hour $\mu \mathrm{g} / \mathrm{ml}$ at week 13 (Table 2 ). The $\mathrm{T}$ cell population also expressed CD38 heterogeneously with an even lower median density than that of B cells (Fig. 2B) and was reduced in peripheral blood after the first infusion of TAK-079 with an $\mathrm{ED}_{50}$ of $30 \mathrm{mg} / \mathrm{kg}$ (Fig. 3D) at a corresponding $C_{\max }$ of $962 \mu \mathrm{g} / \mathrm{ml}$ and an overall mean exposure of 228,000 hour $\mu \mathrm{g} / \mathrm{ml}$ at week 13 (Table 2). Collectively, these doserange finding data indicated that a weekly dose of $3 \mathrm{mg} / \mathrm{kg}$ would sustain a reduction of the total NK, B, and $\mathrm{T}$ cell populations by greater than $80 \%, 60 \%$, and $20 \%$, respectively, from baseline levels in peripheral blood.

The Profile of TAK-079 in Collagen-Induced Arthritis. The potential efficacy of TAK-079 was investigated with a collagen-induced arthritis (CIA) model in cynomolgus monkeys using clinical indices based on the similarity of the monkey immune system, joints, and skeletal anatomy to human counterparts. To induce arthritis, monkeys were treated intradermally on days 0 and 21 with type II collagen (Fig. 1), and the successful immunization of each animal was confirmed by the emergence of anticollagen antibodies (Supplemental Fig. 1). One group of animals was treated on day 7 with a $3 \mathrm{mg} / \mathrm{kg}$ prophylactic TAK-079 treatment regimen that continued for 8 weeks. In the three therapeutic groups, monkeys that had overt disease were randomized and administered a vehicle control, $3 \mathrm{mg} / \mathrm{kg}$ TAK-079, or $0.1 \mathrm{mg} / \mathrm{kg}$ dexamethasone. Therapeutic treatment continued for 5 weeks after initiation of treatment (Fig. 1).

TAK-079 was well tolerated in both the prophylactic and therapeutic regimens. The healthy control monkey gained body weight over time, whereas the collagen-immunized monkeys in the other four groups started to lose body weight from day 7 (Fig. 4A), indicating a systemic impact associated with the development of arthritis. Based on the percentage of change in body weight against baseline body weight upon enrollment, the animals in the prophylactic TAK-079 group,

TABLE 2

Mean serum pharmacokinetic parameters of TAK-079 after an intravenous infusion into female cynomolgus monkeys

\begin{tabular}{llllcrc}
\hline Dose & Dose Schedule & Sample Timing & $N$ & $C_{\max }$ & $\mathrm{AUC}_{366}$ & $T_{1 / 2}$ \\
\hline$m g / k g$ & & & & $\mu g / m l$ & $h \cdot \mu g / m l$ & $h$ \\
0.1 & \multirow{2}{*}{ Weekly } & Week 1 & 7 & 1.77 & 104 & $\mathrm{NC}$ \\
& & Week 13 & 1 & 2.49 & 218 & $\mathrm{NC}$ \\
0.3 & \multirow{2}{*}{ Weekly } & Week 1 & 7 & 4.32 & 327 & $\mathrm{NC}$ \\
& & Week 13 & 2 & 7.78 & 665 & $\mathrm{NC}$ \\
1.0 & Weekly & Week 1 & 7 & 21.2 & 1630 & $\mathrm{NC}$ \\
& & Week 13 & 4 & 28.6 & 2700 & $\mathrm{NC}$ \\
3 & \multirow{2}{*}{ Biweekly } & Week 1 & 3 & 62.1 & 7600 & $\mathrm{NC}$ \\
& & Week 13 & 3 & 90.1 & 18,400 & 237 \\
30 & \multirow{2}{*}{ Biweekly } & Week 1 & 3 & 680 & 92,800 & $\mathrm{NC}$ \\
& & Week 13 & 3 & 962 & 228,000 & $\mathrm{NC}$ \\
80 & \multirow{2}{*}{ Biweekly } & Week 1 & 3 & 1630 & 220,000 & $\mathrm{NC}$ \\
& & Week 13 & 3 & 3140 & 456,000 & 415 \\
\hline
\end{tabular}

$\mathrm{AUC}_{366}$, area under concentration-time curve from dose administration to $366 \mathrm{~h}$ postdose; $N$, number of animals; NC, no change; $T_{1 / 2}$, elimination half-life. 


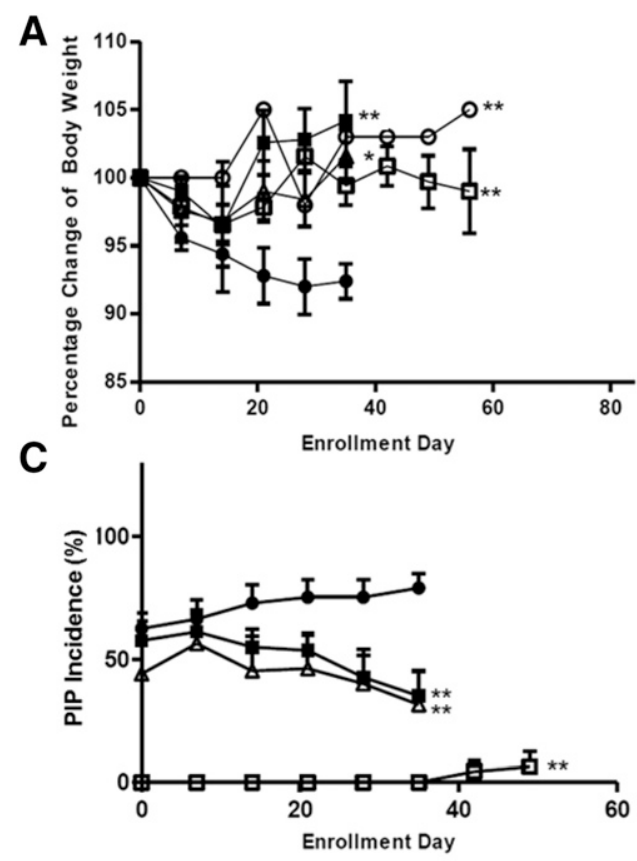

E

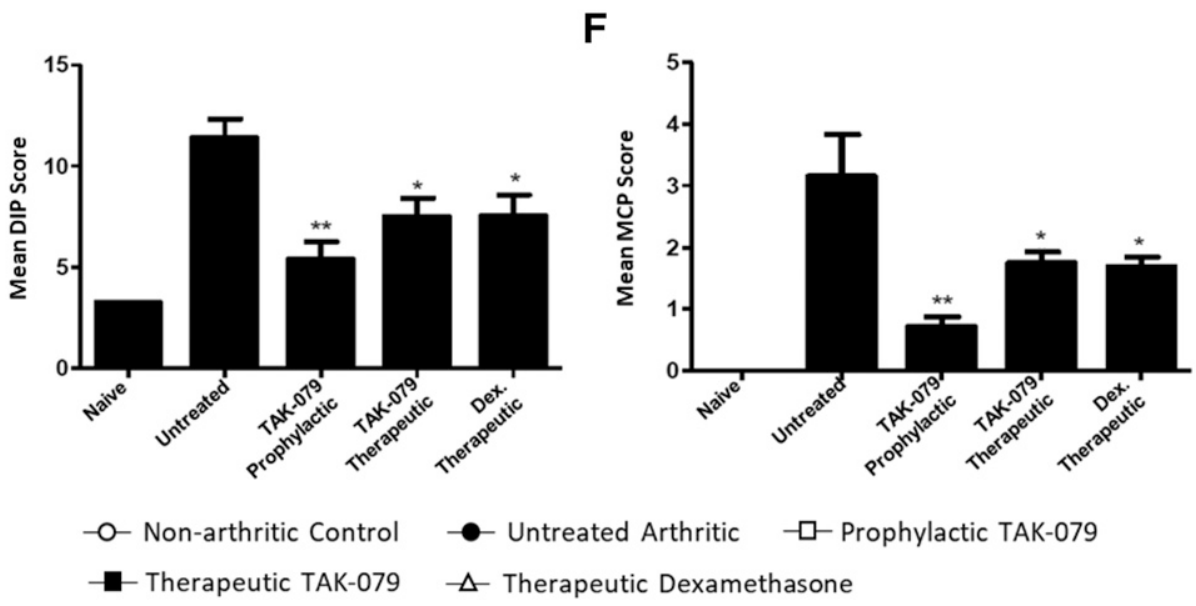

B

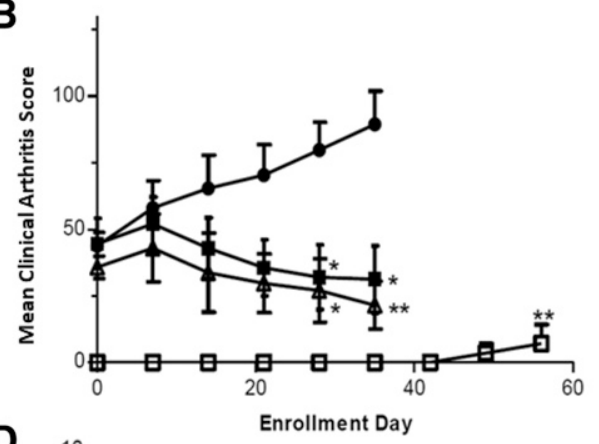

D

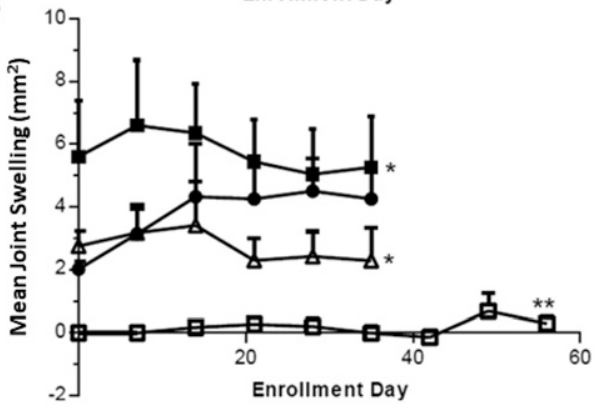

$\mathbf{F}$
Fig. 4. Body weight measurements normalized for percentage of change from the time of enrollment (A). Mean clinical arthritis score from 16 joints (B). The number of PIP joints (C) with joint swelling. The mean oval area of 16 PIP joints (D) were calculated and reported as the mean joint swelling for each animal. Radiographic examination was performed following X-ray imaging for every DIP (E) and MCP (F) joint. Data are the mean \pm S.E. for each group ( $n=1,5,7,5$, and 4, for nonarthritic control animal, untreated arthritic animals, animals treated prophylactically with TAK-079, animals treated therapeutically with TAK-079, and animals treated therapeutically with dexamethasone, respectively). ${ }^{*} P<0.05$ and ${ }^{* *} P<0.01$, compared with the untreated group (oneway ANOVA/Dunnett's multiple comparisons test). therapeutic TAK-079 group, and therapeutic dexamethasone group were found to regain their body weight beginning 14 days after the start of treatment, suggesting a therapeutic benefit from both TAK-079 and the dexamethasone positive control treatment. Weight gain approached near-normal levels in the TAK-079- and dexamethasone-treated monkeys compared with the healthy, untreated control, while arthritic animals treated with vehicle lost weight (Fig. 4A).

The severity of arthritis was assessed using the clinical arthritis score, which is a global assessment of disease activity that considers every measurable joint in the animal over the course of the study using a 192-point scoring system. Vehicletreated animals exhibited progressive disease, with increasing clinical scores over the course of the study (Fig. 4B). Prophylactic exposure to TAK-079 prevented the development of arthritis significantly $(P<0.01)$ compared with the vehicle control. Similarly, therapeutic treatment with TAK-079 or dexamethasone significantly inhibited the development of arthritis compared with the vehicle control $(P<0.05)$ and reduced arthritis scores from the pretreatment baselines (Fig. 4B). Similar effects were observed in the subset of PIP joints with respect to both the number of inflamed PIP joints (Fig. 4C) and the overall mean swelling of all PIP joints (Fig. 4D). To obtain a comprehensive assessment of the arthritic joints and the potential for TAK-079 to have disease modification activity in human arthritis, radiographic examination was performed for every interphalangeal and MCP joint. Prophylactic exposure to TAK-079 prevented damage in PIP (Supplemental Fig. 2), DIP (Fig. 4E), and MCP (Fig. 4F) joints significantly $(P<0.01)$ compared with vehicle control. Similarly, therapeutic exposure to TAK-079 or dexamethasone resulted in significantly less damage $(P<0.05)$ in PIP (Supplemental Fig. 2), DIP (Fig. 4E), and MCP (Fig. 4F) joints than in vehicle control animals.

To characterize components of progressive arthritis, DIP and PIP joints were analyzed histologically with respect to cell infiltration, pannus severity, cartilage damage, bone resorption, and osteophyte formation (Figs. 5 and 6). Prophylactic exposure to TAK-079 resulted in composite scores that were significantly less $(P<0.01)$ than the vehicle control value and comparable in magnitude to animals not immunized with collagen (Fig. 6A). TAK-079 had a similar effect on each 

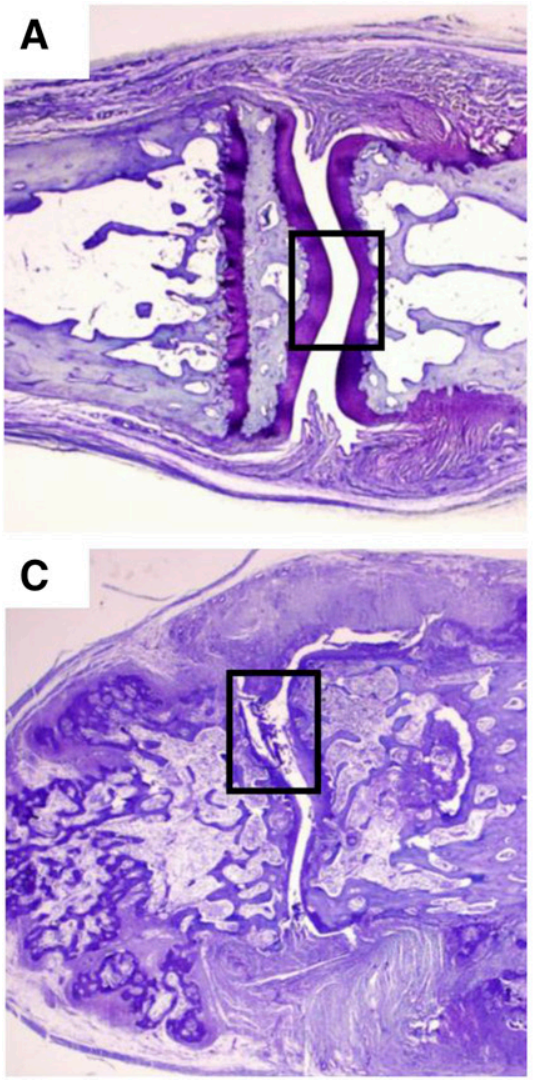

E
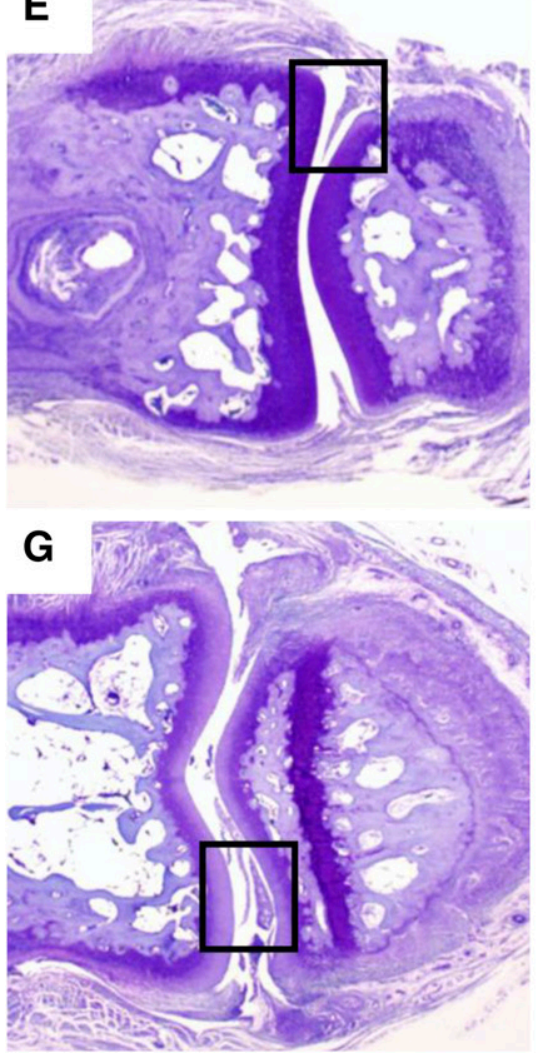
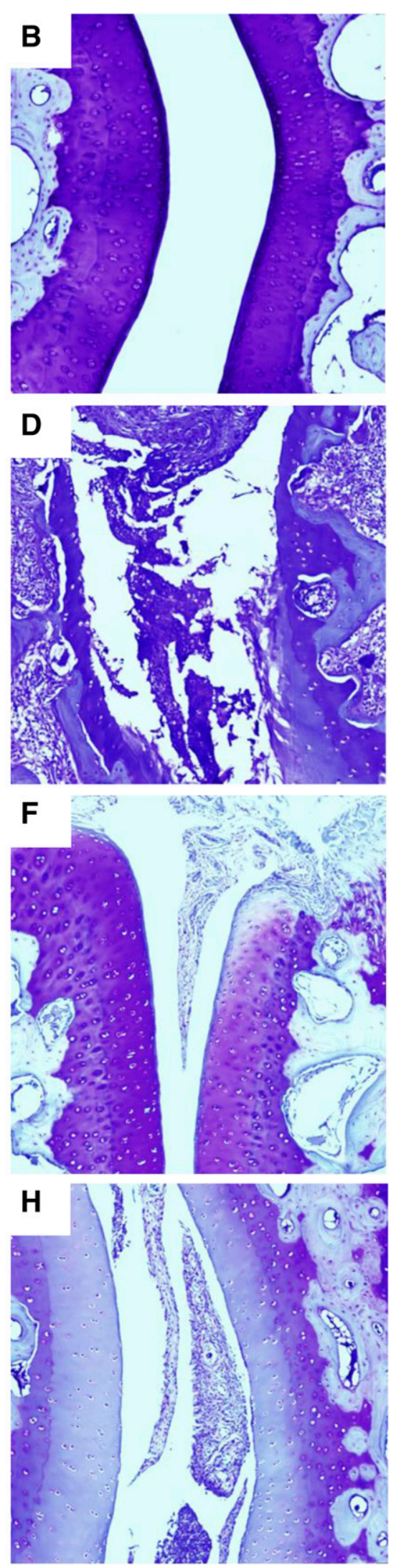

Fig. 5. A representative histopathology section from a PIP joint stained with toluidine blue from a naive animal at original magnification, $1.25 \times(\mathrm{A})$ and $10 \times(\mathrm{B})$, which was scored as follows: cell infiltrate 1; pannus 1 ; cartilage lesion 0 ; bone resorption 0 ; and osteophyte 1 . A PIP joint from an arthritic vehicle control monkey at original magnification, $1.25 \times(\mathrm{C})$ and $10 \times(\mathrm{D})$, which was scored as follows: cell infiltrate 4; pannus 4; cartilage lesion 4; bone resorption 4; and osteophyte 4. A PIP joint from a monkey exposed to TAK-079 prophylactically at original magnification, $1.25 \times(\mathrm{E})$ and $10 \times(\mathrm{F})$, which was scored as follows: cell infiltrate 1; pannus 1 ; cartilage lesion 0 ; bone resorption 0 ; and osteophyte 1. A PIP joint from a monkey treated therapeutically with TAK-079 at original magnification, $1.25 \times(\mathrm{G})$ and $10 \times(\mathrm{H})$, which was scored as follows: cell infiltrate 2 ; pannus 2 ; cartilage lesion 2 ; bone resorption 1 ; and osteophyte 2 . Black boxes in $1.25 \times$ magnification images denote the location of the corresponding $10 \times$ magnification image. component: scores were significantly less $(P<0.01)$ than the vehicle control value for pannus (Fig. 6B), infiltrating leukocytes (Fig. 6C), cartilage lesions (Fig. 6D), bone resorption (Fig. 6E), and osteophyte formation (Fig. 6F). Similar differences of lesser magnitude were also observed for therapeutic treatment with TAK-079 or dexamethasone 
A

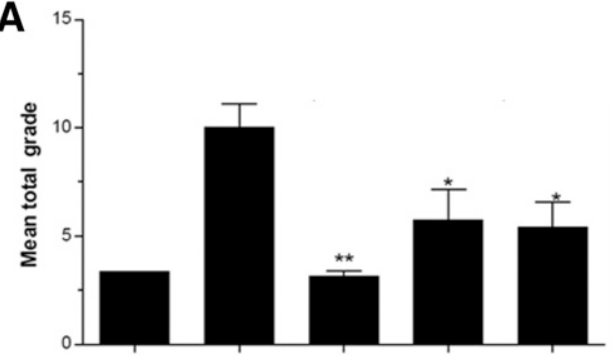

C

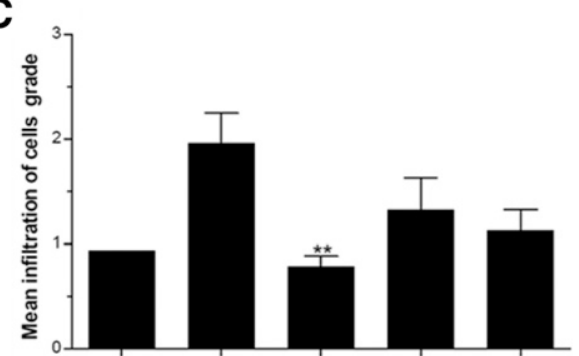

E

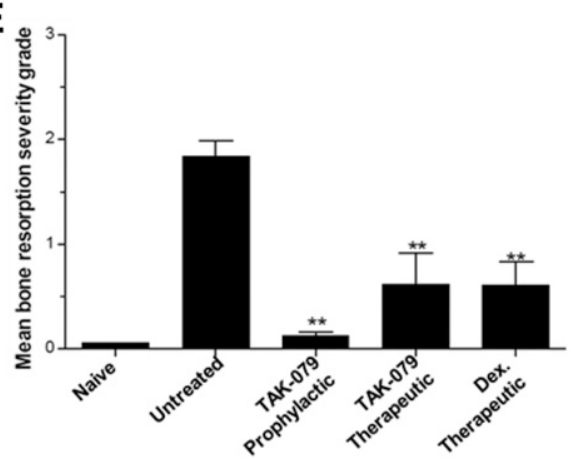

B

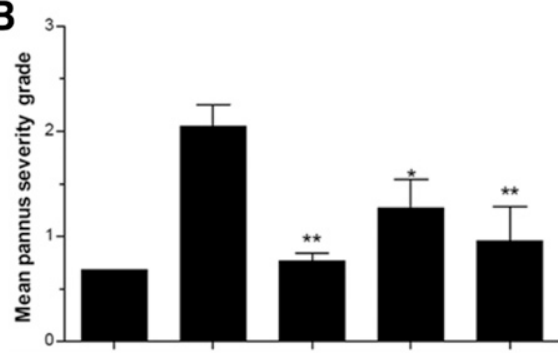

D

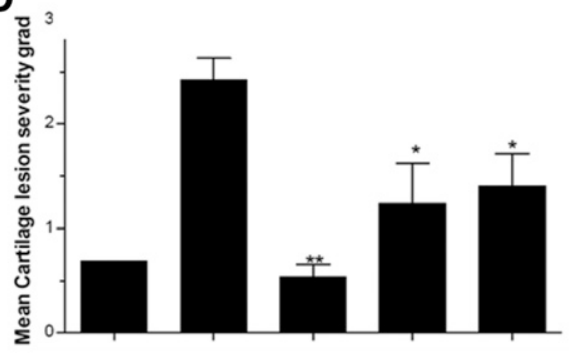

$\mathbf{F}$

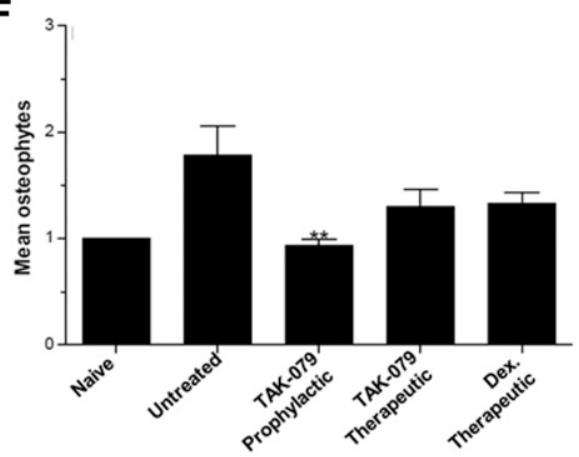

Fig. 6. Quantitative histomorphometry of DIP joints performed blinded using toluidine blue stained sections $(32 \times$ 22 animals $=704$ slides) to assess total grade (A), pannus (B), cell infiltration (C), cartilage lesion (D), bone resorption (E), and osteophyte formation $(\mathrm{F})$. Data are the mean \pm S.E. for each group $(n=1,5,7$, 5 , and 4 , for nonarthritic control animal, untreated arthritic animals, animals treated prophylactically with TAK-079, animals treated therapeutically with TAK-079, and animals treated therapeutically with dexamethasone, respectively). $* P<0.05$ and $* * P<0.01$, compared with the untreated group (one-way ANOVA/Dunnett's multiple comparisons test)
(Fig. 6, A-E), although not all differences reached statistical significance.

Quantitative histomorphometry was performed on all DIP and PIP joints in blind by a board-certified, veterinary pathologist, although only DIP results are presented in Fig. 7, including total articular cartilage area (Fig. 7A), thickness of damaged articular cartilage (Fig. 7B), percentage of damaged articular surface (Fig. 7C), and osteophyte area versus total periosteal surface (Fig. 7D). All of the parameters illustrated that prophylactic exposure to TAK079 significantly prevented the development of articular damage. Therapeutic treatment with TAK-079 reduced the severity of disease, although some histomorphometric measures did not achieve statistical significance. The therapeutic effects of TAK-079 were similar to dexamethasone administered therapeutically.

Levels of C-reactive protein (CRP) (Fig. 8A), alkaline phosphatase (ALP) (Fig. 8B), and albumin (Supplemental Fig. 3) correlated with disease severity. Prophylactic treatment with TAK-079 prevented the inflammation-associated increases in CRP (Fig. 8A) and ALP (Fig. 8B) observed in the vehicle control animal. Therapeutic treatment with TAK-079 caused a rapid decrease in CRP and ALP, whereas prolonged treatment with dexamethasone was required to reduce CRP and ALP levels (Fig. 8). No evidence of liver damage was found in serum chemistry parameters (e.g., increased alanine aminotransferase or aspartate transaminase), which suggests that the increased ALP was due to development of bone disease in animals with CIA, and the reduced ALP was due to reduced bone damage in TAK-079-exposed animals. Serum chemistry values for creatinine, blood urea nitrogen, glucose, and total protein varied over time but showed no consistent correlation with arthritis severity or treatment regimen (data not shown).

Hematology, complete blood count, and differential analyses were conducted during the study and the key parameters were reported. No change was observed in levels of RBCs after exposure to TAK-079 or dexamethasone (Fig. 9A). Furthermore, the hematocrit count was decreased after development of arthritis and increased back toward the naive control levels after treatment with either TAK079 or dexamethasone (Fig. 9B). Reticulocytes were elevated after development of arthritis, and both TAK-079 and dexamethasone treatment reduced the reticulocyte count toward the normal level found in the naive control (Fig. 9C). Both platelet and neutrophil levels were elevated with arthritis, and TAK-079 treatment reduced both platelet and neutrophil levels toward the naive control, whereas dexamethasone had no effect (Fig. 9, D and E, respectively). In contrast, total lymphocyte levels were decreased with disease relative to the naive control and treatment with TAK-079 (as expected) and further reduced lymphocyte levels, whereas treatment with dexamethasone had no effect (Fig. 9F). 
A

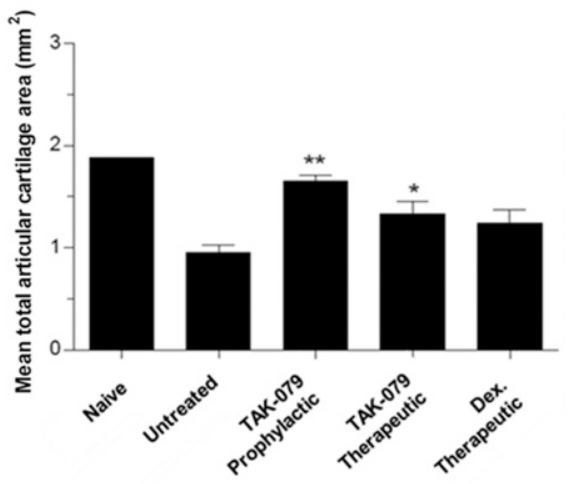

C

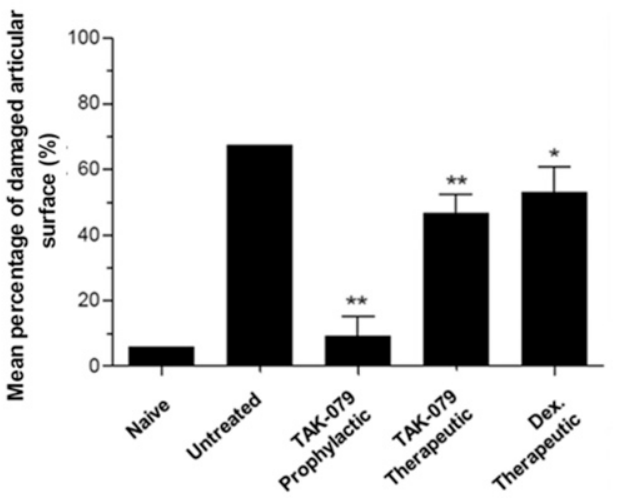

B

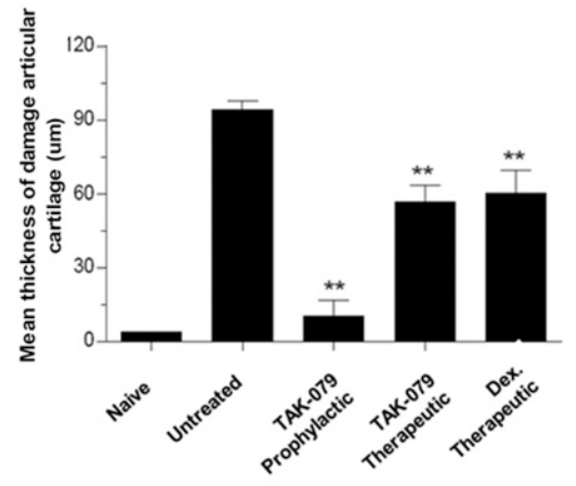

D

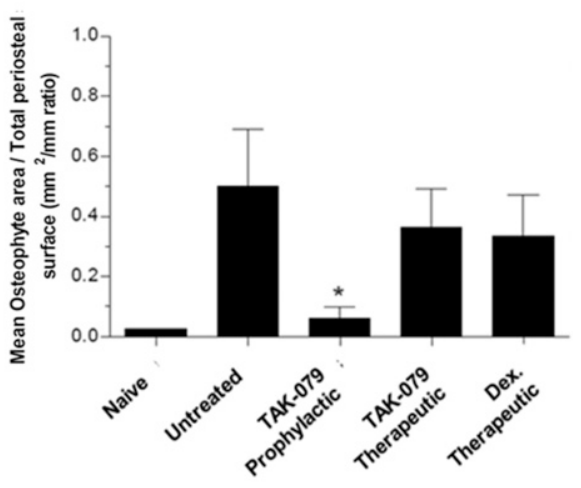

Fig. 7. Quantitative histomorphometry of the articular area and surface of DIP joints was performed blinded by a bone histopathologist using toluidine blue-stained slides $(32 \times 22$ animals $=704$ slides $)$. The individual results from each animal were plotted as the mean \pm S.E. for each group. Statistical analysis was conducted as specified in the Methods: total articular cartilage area (A), thickness of damaged articular cartilage (B), percentage of damaged articular surface (C), and osteophyte area vs. total periosteal surface (D). Data are the mean \pm S.E. for each group $(n=1,5,7,5$, and 4 , for nonarthritic control animal, untreated arthritic animals, animals treated prophylactically with TAK-079, animals treated therapeutically with TAK-079, and animals treated therapeutically with dexamethasone, respectively). $* P<0.05$ and $* * P<0.01$, compared with the untreated group (one-way ANOVA/ Dunnett's multiple comparisons test). Dex., dexamethasone.
Among the subsets of lymphocytes in peripheral blood, NK cells were reduced $>95 \%$ below baseline levels (Fig. 10A) within 24 hours of exposure to TAK-079, whereas the maximum reductions of baseline levels of B cells (Fig. 10B), T cells (Fig. 10C), and monocytes (Fig. 10D) were 60\%, 55\%, and $50 \%$, respectively. NK and B cell reductions were sustained throughout dosing, whereas T-cell and monocyte reductions were transient and only observed after the first infusion. A similar reduction pattern was seen in each cell population after TAK-079 prophylactic treatment, except that this group of animals had lower monocyte levels before treatment and the monocyte levels did not change in response to treatment. No differences were seen in NK, B, and T cells or monocyte counts between vehicle and dexamethasone-treated animals (Fig. 10).

Serum bioanalysis was conducted to measure concentrations of TAK-079 and anti-TAK-079 antibodies. Substantial exposure was achieved in each animal dosed prophylactically (Fig. 11A) or therapeutically (Fig. 11B) with the $C_{\max }$ value ranging from 24 to $97 \mu \mathrm{g} / \mathrm{ml}$. All animals exposed to TAK-079 exhibited trough concentrations that exceeded the $\mathrm{EC}_{50}$ value for CD38 saturation (Fig. 2A) and NK cell lysis (Fig. 2C) in vitro. Anti-TAK-079 antibodies were detected in four of seven animals in the prophylactic group (Fig. 11C) from 14 to 30 days after initial dosing and until the end of the study. Two animals exhibited high titers, which corresponded
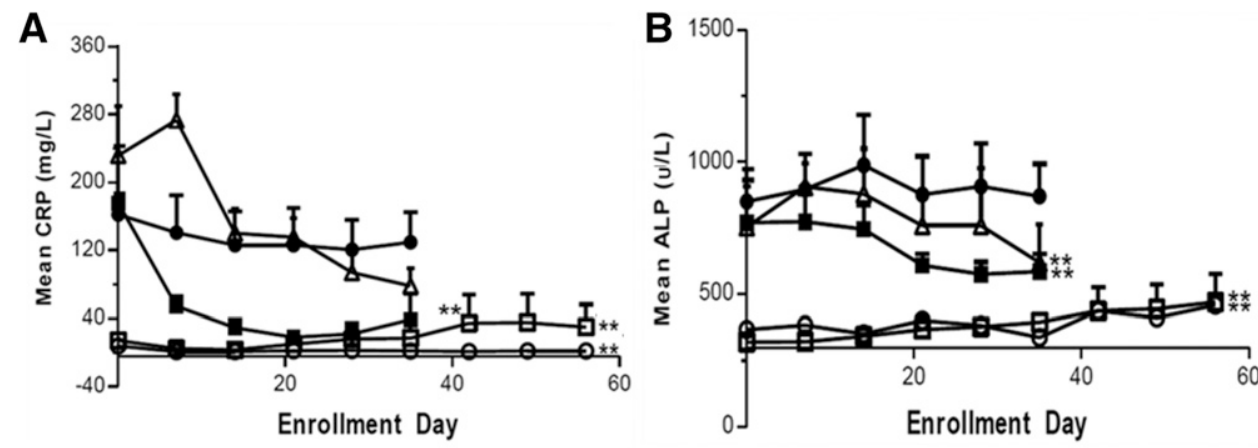

-O- Non-arthritic Control

Untreated Arthritic

- Prophylactic TAK-079
Fig. 8. Serum chemistry levels of CRP (A) and $\operatorname{ALP}(\mathrm{B})$ over time. Data are the mean \pm S.E. for each group $(n=1,5,7,5$, and 4 , for nonarthritic control animal, untreated arthritic animals, animals treated prophylactically with TAK-079, animals treated therapeutically with TAK-079, and animals treated therapeutically with dexamethasone, respectively). ${ }^{*} P<0.05$ and $* * P<0.01$, compared with the untreated group (one-way ANOVA/Dunnett's multiple comparisons test). 

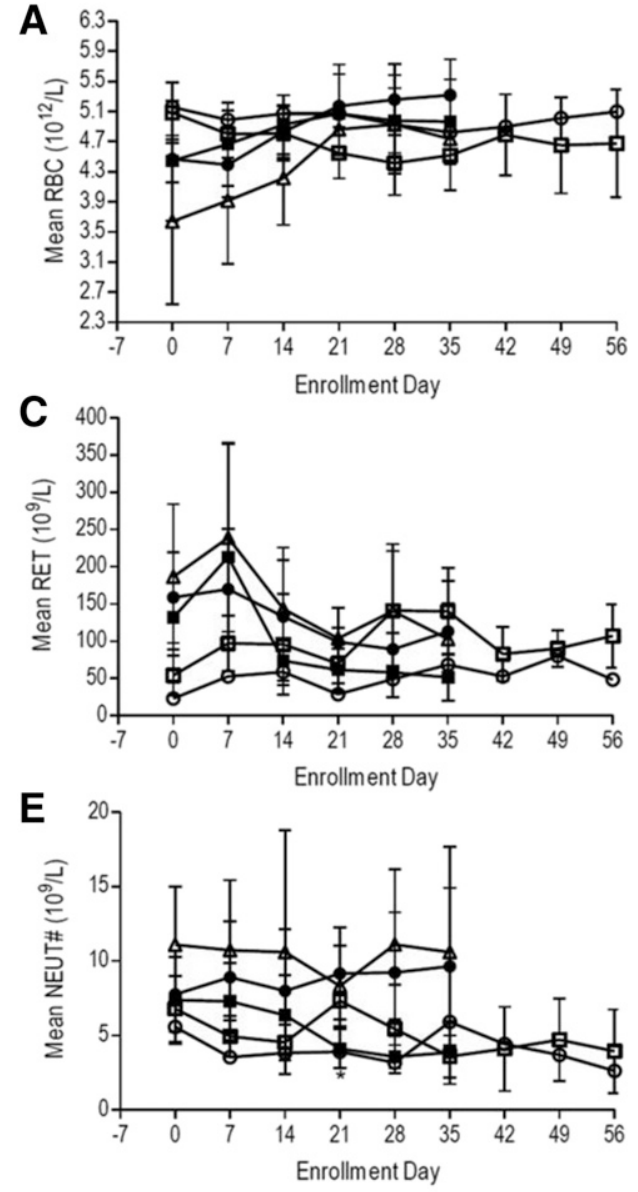

- - - Non-arthritic Control $\quad-$ - Untreated Arthritic $\quad-\square$-Prophylactic TAK-079

Therapeutic TAK-079 $-\Delta$ - Therapeutic Dexamethasone
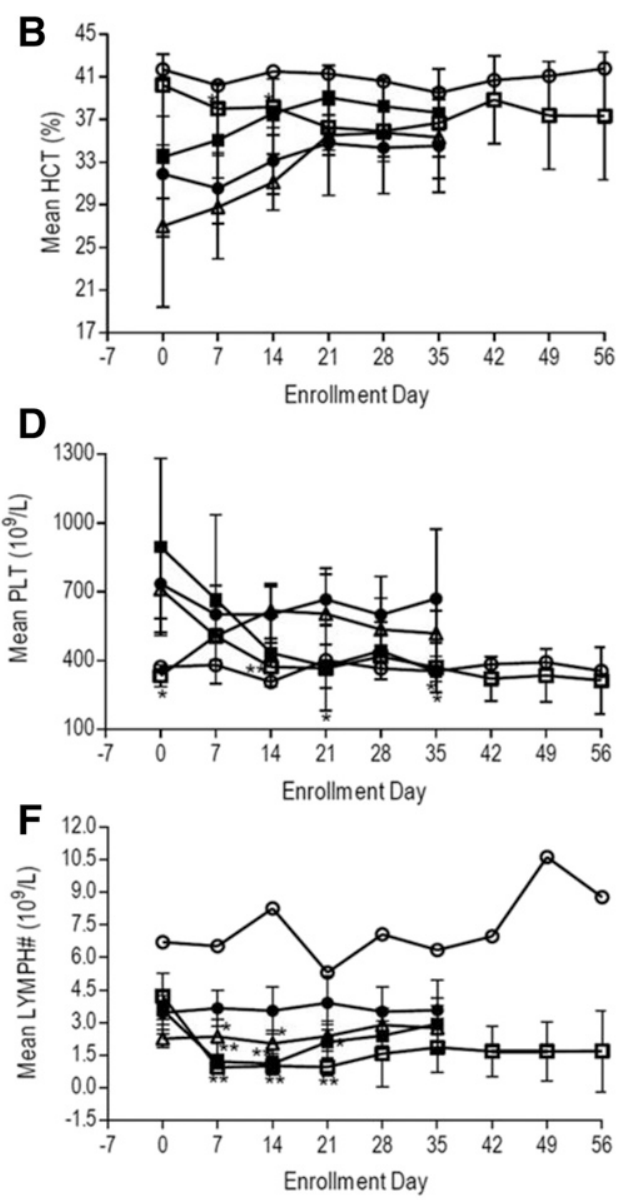

Fig. 9. Levels of red blood cells (A), hematocrit (B), reticulocytes $(\mathrm{C})$, platelets (D), neutrophils (E), and lymphocytes (F) in animals over time. Data are the mean \pm S.E. for each group $(n=1,5,7,5$, and 4 , for nonarthritic control animal, untreated arthritic animals, animals treated prophylactically with TAK-079, animals treated therapeutically with TAK-079, and animals treated therapeutically with dexamethasone, respectively). $* P<0.05$ and ${ }^{* * P}<0.01$, compared with the untreated group (one-way ANOVA/Dunnett's multiple comparisons test). ANOVA, analysis of variance; HCT, hematocrit; LYMPH, lymphocyte; NEUT, neutrophil; PLT, platelet; RET, reticulocyte. to low concentrations of TAK-079 in these animals by day 31 (Fig. 11A), indicating that these anti-TAK-079 antibodies may be affecting clearance. Anti-TAK-079 antibodies were also detected in four of five animals in the therapeutic group (Fig. 11D) from 21 days after initial dosing until the end of the study and two animals also exhibited high titers, which corresponded to low concentrations of TAK-079 in these animals by the end of the study (Fig. 11B). Nonetheless, all animals were included in the data analyses because most target cells remained reduced from baseline levels throughout the duration of the study (Fig. 10, A, B, and D), with the exception of $\mathrm{T}$ cells after the second therapeutic dose (Fig. 10C).

\section{Discussion}

A deficiency of CD38 in mice was reported to result in attenuated forms of CIA (Rosal-Vela et al., 2016), illustrating a nonredundant function(s) of this molecule in a model of autoimmune disease; however, the role of CD38 cells in primate models has not been investigated. In addition, numerous studies have indicated that the overall level of CD38 expression on peripheral blood cells correlates positively with disease activity in RA and SLE patients (Kraan et al., 1999; Vital et al., 2011; Cole et al., 2018). The anti-CD38
mAb TAK-079 depleted plasma cells (Smithson et al., 2017; Cole et al., 2018) in blood and bone marrow samples from patients with RA (Wang et al., manuscript in preparation) and SLE (Wang et al., 2016) in vitro. In contrast to other antiCD38 mAbs in development (e.g., daratumumab, isatuximab, and MOR202), TAK-079 binds to CD38 expressed by cynomolgus monkeys and provides the unique opportunity to determine if reducing the levels of cells expressing CD38 would prevent and/or ameliorate inflammation and tissue damage in a nonhuman primate model of autoimmunity.

The cynomolgus monkey was determined to be a suitable model for assessing potential effects of TAK-079 in an autoimmune disease because the CIA in these monkeys features a symmetrical small joint polyarthritis that resembles human RA and lupus arthritis (Mihara et al., 2001; Kato et al., 2008; Uchiyama et al., 2008a,b), the TAK-079bound cells are similar between these species (Table 1), and TAK-079 binds to monkey CD38 with high affinity (Fig. 2). We concluded that a weekly TAK-079 dose of $3 \mathrm{mg} / \mathrm{kg}$ would be adequate for assessing the potential role of CD38 in CIA because dose-range studies in healthy monkeys indicated that a weekly dose of $3 \mathrm{mg} / \mathrm{kg}$ of TAK- 079 would reduce the total NK, B, and T cell populations by more than $80 \%, 60 \%$, and $20 \%$, respectively, from baseline levels in peripheral blood (Fig. 3, B-D). Similar reductions in NK, B, and T cells 

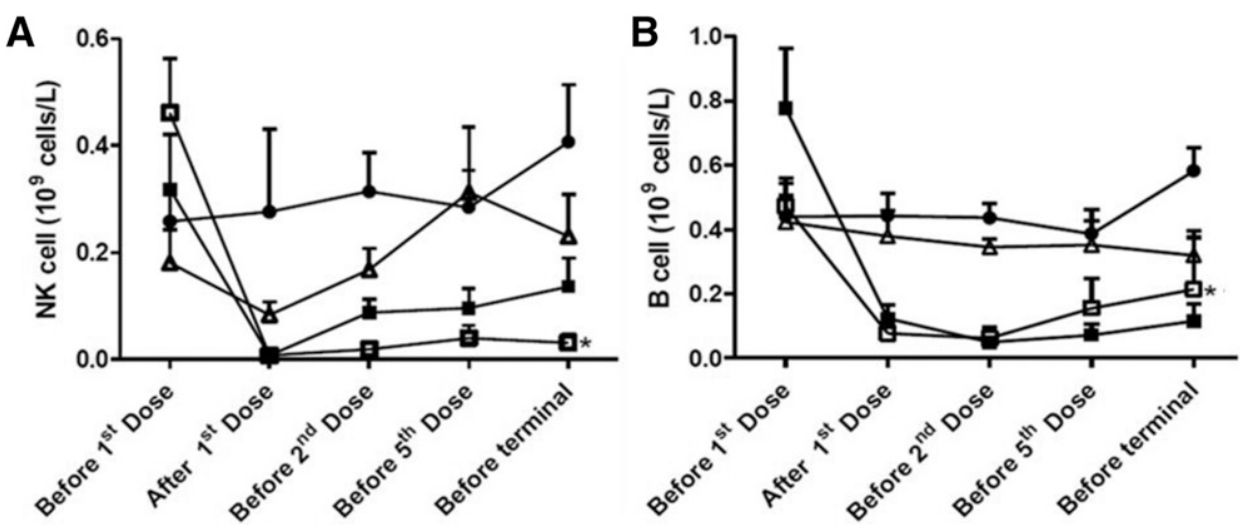

C
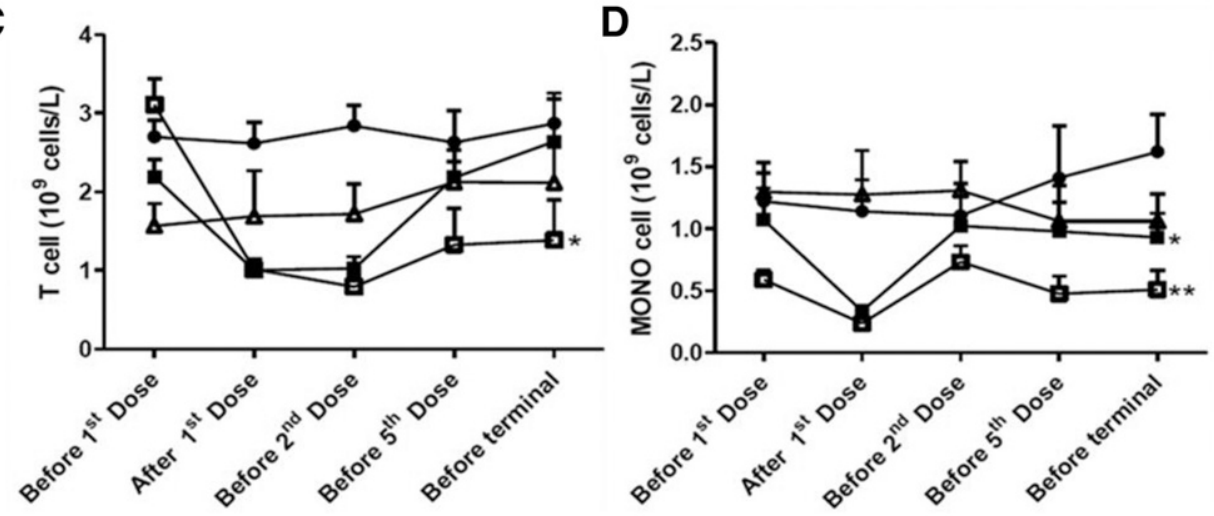

Untreated Arthritic

$\neg-$ Prophylactic TAK-079

Therapeutic TAK-079 $\triangle$ - Therapeutic Dexamethasone
Fig. 10. Levels of NK cells (A), B cells (B), $\mathrm{T}$ cells $(\mathrm{C})$, and monocytes (D) in peripheral blood over time. Data are the mean \pm S.E. for each group $(n=1,5,7,5$, and 4 , for nonarthritic control animal, untreated arthritic animals, animals treated prophylactically with TAK-079, animals treated therapeutically with TAK-079, and animals treated therapeutically with dexamethasone, respectively). $* P<0.05$ and $*_{*} P<0.01$, compared with the untreated group (one-way ANOVA/Dunnett's multiple comparisons test). MONO, monocyte. were achieved in the CIA model for prophylactic dosing (Fig. 10, A-C) despite the emergence of anti-TAK-079 antibodies in some animals (Fig. 11, C and D). The decrease in concentration of TAK-079 over time in three animals exposed prophylactically (Fig. 11A) indicates that these antibodies may have increased clearance. Nonetheless, NK, $\mathrm{B}$, and $\mathrm{T}$ cells had not recovered to baseline levels by study termination (Fig. 10, A-C), indicating that the exposures to TAK-079 were sufficient to maintain PD effects throughout the investigation. Therefore, these animals were included in all analyses. This was also generally true for therapeutic treatment with TAK-079: NK and B cells had not recovered to baseline levels by study termination (Fig. 10, A and B), indicating that exposures to TAK-079 were sufficient to maintain PD effects throughout the investigation. In contrast, total $\mathrm{T}$ cell counts had recovered to baseline levels by study termination (Fig. 10C), which may have resulted from reconstitution with naive $\mathrm{T}$ cells that do not express CD38 and are not depleted by TAK-079.

Prophylactic administration of TAK-079 was included in this study as a comparator to assess the relative effectiveness of therapeutic administration. Prophylactic administration of TAK-079 prevented arthritis development, as illustrated consistently across all assessments, whereas therapeutic treatment with TAK-079 inhibited the development of arthritis and articular damage (Figs. 4-7). Histologic assessment of joints demonstrated that TAK-079 exerted relatively broad effects, preventing pannus formation (Fig. 6B), infiltration (Fig. 6C), cartilage lesions (Fig. 6D), bone resorption (Fig. 6E), and osteophyte formation (Fig. 6F). It is noteworthy that therapeutic treatment with TAK-079 and dexamethasone also inhibited these progressive histologic changes, albeit to a lesser magnitude than prophylactic administration. The arthritis scores decreased over time with therapeutic treatment (Fig. 4, B-D), indicating potential reversal of damage. Collectively, these data demonstrated consistent diseasemodifying effects with exposure to TAK-079 prophylactically and therapeutically.

The effects of these therapeutic TAK-079 and dexamethasone treatments appear comparable to one another for the regimes investigated. Therapeutic use of steroids, such as dexamethasone, is highly effective in treating human autoimmune diseases, including RA and SLE; however, deleterious side effects (e.g., osteoporosis, hypertension, diabetes, weight gain, cataracts, glaucoma, thinning of the skin, and bruising) restrict chronic use of these therapeutics. The potential for targeted CD38 cell depletion to provide substantial clinical efficacy in human autoimmune diseases without the deleterious side effects of steroids or other contemporary therapies warrants future clinical investigation.

The prophylactic and therapeutic effects of TAK-079 were associated with sustained reductions in the blood levels of total lymphocytes (Fig. 9F) and NK, B, and T cells 

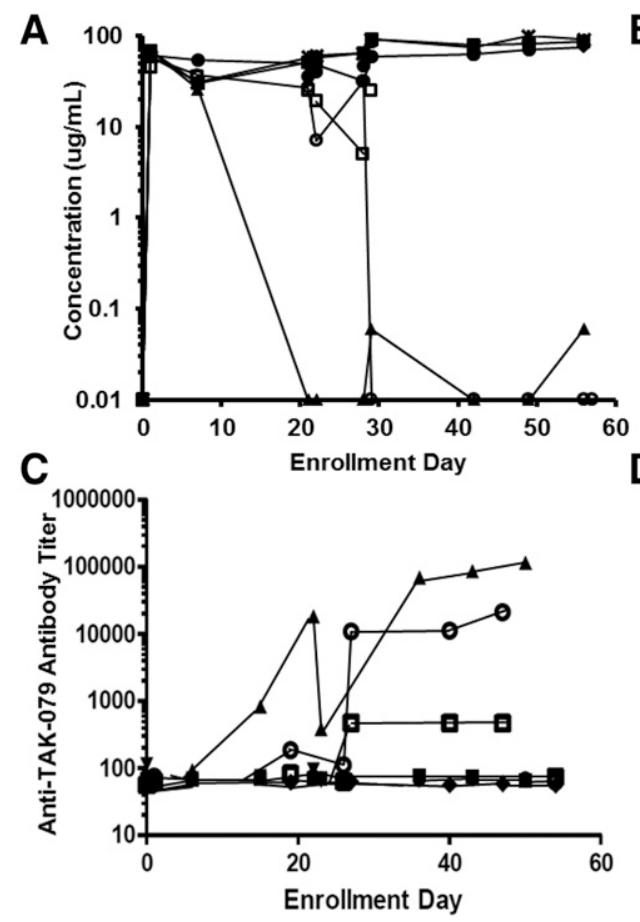
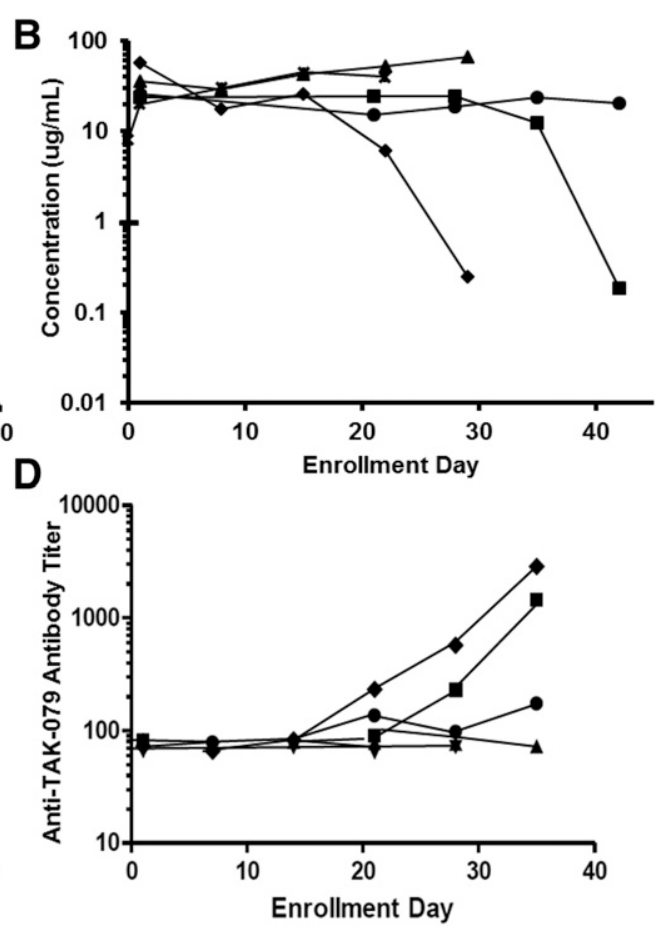

Fig. 11. Serum concentrations of TAK-079 in individual monkeys when administered prophylactically (A) and therapeutically (B). Serum concentrations of anti-TAK-079 antibodies in individual monkeys when administered prophylactically $(\mathrm{C})$ and therapeutically (D). Each symbol denotes data from an individual animal.
(Fig. 10, A-C); transient reduction in monocytes (Fig. 10D); and no changes in RBCs (Fig. 9A), platelets (Fig. 9D), and neutrophils (Fig. 9E). These PD data illustrate that differences exist in the sensitivity of cells expressing CD38 to reduction by TAK-079. Reduction generally correlated with the density of CD38 expression by the cell; the NK cell population uniformly expressed the highest median density of CD38 in all cell types examined (Fig. 2B) and was most sensitive to TAK-079 (Figs. 3B and 10A). The highest density of CD38 expressed on B cells was approximately 3 -fold lower than on NK cells (Fig. 2B), and the B cell population was less sensitive to TAK-079 than NK cells (Figs. 3C and 10A). CD38 was generally expressed at lower median densities on $\mathrm{T}$ cells than on $\mathrm{B}$ cells (Fig. 2B), and $\mathrm{T}$ cells were less sensitive to reduction by TAK-079 than were B and NK cells (Figs. 3D and 10C). Cells that express low densities of CD38 (e.g., RBCs) or do not express CD38 (e.g., neutrophils) were not affected by TAK-079 (Fig. 9, A and $\mathrm{E}$ ). An exception was monocytes, which expressed CD38 uniformly at intermediate densities and were only transiently reduced by TAK-079 (Fig. 10D). The kinetics of the transient reduction in monocytes is distinct from the sustained reduction observed for $\mathrm{B}, \mathrm{T}$, and $\mathrm{NK}$ cells and indicates distinct mechanisms. Direct cytolysis of $\mathrm{NK}$ cells by TAK-079 was observed in vitro (Fig. 2C), and sustained reduction in NK cells occurred after a single dose of TAK-079 in vivo (Fig. 3; Table 2), which indicates that complement-dependent cytotoxicity and/or antibodydependent cell-mediated cytotoxicity mediated NK cell reductions in vivo. In contrast, monocytes were not cytolysed in vitro (data not shown) and did not exhibit sustained reduction in vivo (Fig. 10D), which indicates that an alternate mechanism (e.g., margination) mediated transient reductions in vivo. Resistance of human monocytes to cytolysis by TAK-079 has also been observed in healthy subjects (Fedyk et al., 2018) and described for daratumumab in multiple myeloma patients (Nijhof et al., 2016). The expression of inhibitors of complement-dependent cytotoxicity and antibody-dependent cell-mediated cytotoxicity by human monocytes did not correlate significantly with resistance to cytolysis by daratumumab, and it remains unknown why monocytes are relatively insensitive to daratumumab and TAK-079.

While the reduction in NK cells by TAK-079 is qualitatively consistent with NK cell reduction by daratumumab in refractory myeloma patients, quantitative differences exist. The intravenous infusion dose $(0.3 \mathrm{mg} / \mathrm{kg})$ and the maximal concentration $\left(C_{\max }=4.32 \mu \mathrm{g} / \mathrm{ml}\right)$ of TAK-079 required to maintain peripheral blood $\mathrm{NK}$ cells at $50 \%$ below baseline levels in monkeys (Fig. 3B) were approximately 80- and 116fold lower than the corresponding intravenous infusion dose $(24 \mathrm{mg} / \mathrm{kg})$ and the maximal concentration $\left(C_{\max }=\sim 573\right.$ $\mu \mathrm{g} / \mathrm{ml}$ ) required for comparable reductions of NK cells by daratumumab in refractory myeloma patients (Casneuf et al., 2017; Clemens et al., 2017). This difference does not appear to be attributable to differences in binding affinities; TAK-079 binds to $\mathrm{CHO}$ cells expressing monkey CD38 with an $\mathrm{EC}_{50}$ value of $4.5 \mathrm{nM}$ (approximately $700 \mathrm{ng} / \mathrm{ml}$ ), which is similar to daratumumab binding to $\mathrm{CHO}$ cells expressing human CD38 $\left(\mathrm{EC}_{50}=470 \mathrm{ng} / \mathrm{ml}\right)$ (Center for Drug Evaluation and Research, 2015). Alternatively, the observed difference may be due to another factor(s). Nonetheless, a more definitive comparison requires $\mathrm{PK}$ and $\mathrm{PD}$ data for TAK-079 in refractory myeloma patients because daratumumab does not crossreact with CD38 from mouse, rat, rabbit, pig, and cynomolgus and rhesus monkeys (European Medicines Agency's Committee for Medicinal Products for Human Use, 2016).

In conclusion, a reduction in cells expressing CD38 with the cytolytic antibody TAK-079 prevented the development of CIA in monkeys when administered prophylactically and reversed disease progression when administered therapeutically. A 
previous study utilizing blood and bone marrow samples from SLE patients demonstrated that TAK-079 depleted $80 \%$ of short- and long-lived plasma cells and reduced autoantibodies (e.g., VH4-34 9G4+, anti-Ro, and anti-double-stranded DNA) in vitro (Wang et al., 2016). These collective data indicate that this therapeutic strategy may be effective in treating human RA and SLE, as well as other autoimmune diseases.

\section{Acknowledgments}

The authors acknowledge Kathleen Elias and Martin Dahl for seminal contributions to these experiments. Writing and editorial support were provided by Shaw Yang, Calogera McCormick, and Jason R. Buck (Synchrogenix, a Certara company).

\section{Authorship Contributions}

Participated in research design: Fedyk, Idamakanti, Korver, Shi,

Xia, Wagoner, Yuan, Zalevsky.

Conducted experiments: Idamakanti, Shi, Xia, Wagoner.

Contributed new reagents or analytic tools: Idamakanti, Shi, Xia, Wagoner.

Performed data analysis: Carsillo, Fedyk, Idamakanti, Korver,

McLean, Shi, Xia, Wagoner, Yuan, Zalevsky, Smithson.

Wrote or contributed to the writing of the manuscript: Carsillo, Fedyk, Korver, Smithson, Yuan.

\section{References}

Alexander T, Sarfert R, Klotsche J, Kühl AA, Rubbert-Roth A, Lorenz HM, Rech J, Hoyer BF, Cheng Q, Waka A, et al. (2015) The proteasome inhibitior bortezomib depletes plasma cells and ameliorates clinical manifestations of refractory systemic lupus erythematosus. Ann Rheum Dis 74:1474-1478.

Banchereau R, Hong S, Cantarel B, Baldwin N, Baisch J, Edens M, Cepika AM, Acs $\mathrm{P}$, Turner J, Anguiano E, et al. (2016) Personalized immunomonitoring uncovers molecular networks that stratify lupus patients. Cell 165:551-565.

Casneuf T, Xu XS, Adams HC III, Axel AE, Chiu C, Khan I, Ahmadi T, Yan X, Lonial $\mathrm{S}$, Plesner T, et al. (2017) Effects of daratumumab on natural killer cells and impact on clinical outcomes in relapsed or refractory multiple myeloma. Blood Adv 1:2105-2114

Center for Drug Evaluation and Research (2015) Application Number: 7610360rig1s000 Pharmacology Review(s).

Clemens PL, Yan X, Lokhorst HM, Lonial S, Losic N, Khan I, Jansson R, Ahmadi T, Lantz K, Zhou H, et al. (2017) Pharmacokinetics of daratumumab following intravenous infusion in relapsed or refractory multiple myeloma after prior proteasome inhibitor and immunomodulatory drug treatment. Clin Pharmacokinet 56:915-924.

Cole S, Walsh A, Yin X, Wechalekar MD, Smith MD, Proudman SM, Veale DJ, Fearon U, Pitzalis C, Humby F, et al. (2018) Integrative analysis reveals CD38 as a therapeutic target for plasma cell-rich pre-disease and established rheumatoid arthritis and systemic lupus erythematosus. Arthritis Res Ther 20:85.

Deane KD (2014) Preclinical rheumatoid arthritis (autoantibodies): an updated review. Curr Rheumatol Rep 16:419.

European Medicines Agency's Committee for Medicinal Products for Human Use (2016) Assessment report: Darzalex; International non-proprietary name: daratumumab; Procedure No. EMEA/H/C/004077/II/0002. 23 February 2017.

Fedyk ER, Berg D, Smithson G, Estevam J, Mclean L, Allikmets K, and Palumbo A (2018) A single administration of the cytolytic CD38 antibody TAK-079 to healthy subjects: tolerability, pharmacokinetics and pharmacodynamics. Blood 132:3249.

Grammer AC, Slota R, Fischer R, Gur H, Girschick H, Yarboro C, Illei GG, and Lipsky PE (2003) Abnormal germinal center reactions in systemic lupus erythematosus demonstrated by blockade of CD154-CD40 interactions. J Clin Invest 112:1506-1520.
Hale M, Rawlings DJ, and Jackson SW (2018) The long and the short of it: insights into the cellular source of autoantibodies as revealed by B cell depletion therapy. Curr Opin Immunol 55:81-88.

Kato A, Matsuo S, Takai H, Uchiyama Y, Mihara M, and Suzuki M (2008) Early effects of tocilizumab on bone and bone marrow lesions in a collagen-induced arthritis monkey model. Exp Mol Pathol 84:262-270.

Kraan MC, Haringman JJ, Post WJ, Versendaal J, Breedveld FC, and Tak PP (1999) Immunohistological analysis of synovial tissue for differential diagnosis in early arthritis. Rheumatology (Oxford) 38:1074-1080.

Krejcik J, Casneuf T, Nijhof IS, Verbist B, Bald J, Plesner T, Syed K, Liu K, van de Donk NW, Weiss BM, et al. (2016) Daratumumab depletes CD38+ immune regulatory cells, promotes T-cell expansion, and skews T-cell repertoire in multiple myeloma. Blood 128:384-394.

Kubo S, Nakayamada S, Yoshikawa M, Miyazaki Y, Sakata K, Nakano K, Hanami K, Iwata S, Miyagawa I, Saito K, et al. (2017) Peripheral immunophenotyping identifies three subgroups based on T cell heterogeneity in lupus patients. Arthritis Rheumatol 69:2029-2037.

Kurts C, Panzer U, Anders HJ, and Rees AJ (2013) The immune system and kidney disease: basic concepts and clinical implications. Nat Rev Immunol 13:738-753.

Martin F and Chan AC (2006) B cell immunobiology in disease: evolving concepts from the clinic. Annu Rev Immunol 24:467-496.

Mihara M, Kotoh M, Nishimoto N, Oda Y, Kumagai E, Takagi N, Tsunemi K, Ohsugi Y, Kishimoto T, Yoshizaki K, et al. (2001) Humanized antibody to human interleukin-6 receptor inhibits the development of collagen arthritis in cynomolgus monkeys. Clin Immunol 98:319-326.

Nijhof IS, Casneuf T, van Velzen J, van Kessel B, Axel AE, Syed K, Groen RW, van Duin M, Sonneveld P, Minnema MC, et al. (2016) CD38 expression and complement inhibitors affect response and resistance to daratumumab therapy in myeloma. Blood 128:959-970.

Nutt SL, Hodgkin PD, Tarlinton DM, and Corcoran LM (2015) The generation of antibody-secreting plasma cells. Nat Rev Immunol 15:160-171.

Radbruch A, Muehlinghaus G, Luger EO, Inamine A, Smith KG, Dörner T, and Hiepe F (2006) Competence and competition: the challenge of becoming a long-lived plasma cell. Nat Rev Immunol 6:741-750.

Rosal-Vela A, Barroso A, Giménez E, García-Rodríguez S, Longobardo V, Postigo J, Iglesias M, Lario A, Merino J, Merino R, et al. (2016) Identification of multiple transferrin species in the spleen and serum from mice with collagen-induced arthritis which may reflect changes in transferrin glycosylation associated with disease activity: the role of CD38. J Proteomics 134:127-137.

Sjöwall C, Hjorth M, and Eriksson P (2017) Successful treatment of refractory systemic lupus erythematosus using proteasome inhibitor bortezomib followed by belimumab: description of two cases. Lupus 26:1333-1338.

Smithson G, Zalevsky J, Korver W, Roepcke S, Dahl M, Zhao L, Yuan J, McLean L and Elias K (2017) TAK-079 is a high affinity monoclonal antibody that effectively mediates CD38 + cell depletion. J Immunol 198 (Supple 1):224.20.

Stohl W, Hiepe F, Latinis KM, Thomas M, Scheinberg MA, Clarke A, Aranow C, Wellborne FR, Abud-Mendoza C, Hough DR, et al.; BLISS-52 Study Group; BLISS-76 Study Group (2012) Belimumab reduces autoantibodies, normalizes low complement levels, and reduces select B cell populations in patients with systemic lupus erythematosus. Arthritis Rheum 64:2328-2337.

Uchiyama Y, Koike N, and Mihara M (2008a) Anemia in monkey collageninduced arthritis is correlated with serum IL-6, but not TNF $\alpha$. Rheumatol Int 28:879-883.

Uchiyama Y, Yorozu K, Hashizume M, Moriya Y, and Mihara M (2008b) Tocilizumab, a humanized anti-interleukin-6 receptor antibody, ameliorates joint swelling in established monkey collagen-induced arthritis. Biol Pharm Bull 31:1159-1163.

Vital EM, Dass S, Buch MH, Henshaw K, Pease CT, Martin MF, Ponchel F, Rawstron AC, and Emery P (2011) B cell biomarkers of rituximab responses in systemic lupus erythematosus. Arthritis Rheum 63:3038-3047.

Wang X, Dahl M, Nguyen D, Jenks S, Cashman K, Lee FEH, McLean L, and Sanz I (2016) The anti-CD38 monoclonal antibody TAK-079 depletes antibody secreting cells from normal and SLE patients (Abstract). Arthritis Rheumatol 68 (Suppl 10): 1085.

Address correspondence to: Dr. Eric R. Fedyk, Takeda Pharmaceuticals Incorporated, 40 Landsdowne Str., Cambridge, MA 02139. E-mail: eric.fedyk@ takeda.com 